\title{
ELECTROCHEMICAL REDUCTION OF 4-AMINOPYRIMIDINE IN AQUEOUS MEDIA
}

\author{
Barbara Czochralska* and Philip J. Elving ${ }^{\dagger}$
}

Department of Chemistry, University of Michigan, Ann Arbor, MI 48109, U.S.A.

\author{
(Received 12 March 1981)
}

\begin{abstract}
The redox and associated chemical behavior of 4-aminopyrimidine (4-AP) and its reduction products in buffered aqueous media have been examined by a variety of electrochemical techniques. In acidic medium (pH 0-2), 4AP undergoes a two-step reduction: $\mathrm{pH}$-dependent wave $I$ corresponds to a threeelectron (3e) process; wave II, which corresponds to a le transfer, is accompanied by catalytic hydrogen discharge. Between $\mathrm{pH} 2$ and 7.5 , only wave $I$ is visible; its height diminishes above pH 4, becoming zero by pH 8. Macroscale electroreduction at potentials on the crests of waves I and II has been followed electrochemically and by ultraviolet spectrophotometry with isolation and identification of the wave I reduction products. The photochemical transformation of the reduction products on ultraviolet irradiation has been examined. The reduction of $4 \mathrm{AP}$ is accompanied by isomerization, ring opening and/or deamination of the primary reduction products and of the resulting secondary chemical products.
\end{abstract}

\section{INTRODUCTION}

In recent years, the polarographic behavior has been extensively investigated of pyrimidines, purines, and their nucleosides, nucleotides and higher polymers ranging in complexity to the nucleic acids[1-5]. Much of this activity has involved cytosine (4-amino-2hydroxypyrimidine) and adenine (6-aminopurine) (Fig. 1); these are the only two of the five commonly encountered nucleic acid bases which are polarographically reducible within the potential range available in aqueous media. The nonreducible bases are uracil, thymine, and guanine; the first two are polarographically reducible in dimethyl sulfoxide medium $[6,7]$.

The electrochemical reduction of cytosine is best seen between pH 4 and $6[8,9]$. Protonation at $N(3)$ is followed by two-electron (2e) reduction of the 3,4 $\mathbf{N}=\mathrm{C}$ bond to form a carbanion which rapidly acquires a proton to form the dihydro derivative; the latter deaminates to form 2-hydroxypyrimidine, which-since it is more readily reduced than cytosine itself-is immediately reduced to a free radical which rapidly dimerizes; the overall process produces a single dme wave, which approaches $3 e$ magnitude; the $3 e$ magnitude is confirmed by coulometry.

The electrochemical reduction of adenine, best seen at and below pH 5, involves protonation at N(1) followed by $2 e$ reductions (with further protonation) of the $1,6 \mathrm{~N}=\mathrm{C}$ and $3,2 \mathrm{~N}=\mathrm{C}$ bonds to form the tetrahydro derivative (seen as a single $4 e d m e$ polarographic wave); the latter compound deaminates (more slowly than cytosine) to regenerate the $1,6 \mathrm{~N}=\mathrm{C}$ bond, which is reduced ( $2 e$ process) as formed[10-12].

Since the pyrimidine $3,4 \mathrm{~N}=\mathrm{C}$ bond is structurally

* Permanent address: Department of Biophysics, Institute of Experimental Physics, University of Warsaw, Warszawa 22, Poland.

To whom correspondence should be addressed. similar to the purine $1,6 \mathrm{~N}=\mathrm{C}$ bond, 4-aminopyrimidine (Fig. 1) is a model compound for both cytosine and adenine, and might provide a link for comparing the latter two compounds. Consequently, this paper describes a detailed investigation of the reduction of 4-aminopyrimidine (4-AP), whose electrochemical behavior in aqueous media up to now has been only scantily studied[3].

4-Aminopyrimidine was reported [13] to produce two polarographic waves at $\mathrm{pH} 1.2\left(E_{1 / 2}=-1.13\right.$ and $-1.23 \mathrm{~V}$ ) with apparent $n$ values of 2 and 1 , and one wave between pH 2.3 and 6.8 (apparent $n$, based on the limiting current, decreases from 3 to 1 ; because of possible current contribution due to hydrogen ion reduction, such evaluation of $n$ is equivocall. Two 4-A P derivatives have been polarographically examined; 4 amino-2,6-dimethylpyrimidine gives a single wave in acidic and slightly basic media, whose $I_{\mathrm{d}}$ between $\mathrm{pH} 2$ and 5 corresponds to a $3 e$ process [8]. The 2,5-dimethyl derivative is reported to undergo a $3 e$ reduction [14].

It developed in this study of 4-AP that the instability of the primary electrolytic products, as well as that of the secondary products, results in a much more complicated reaction path than had been expected or had been previously reported for pyrimidines. The results amply illustrate the dangers, which may be inherent, in deducing an electrolytic reaction mechanism from polarographic curves alone.
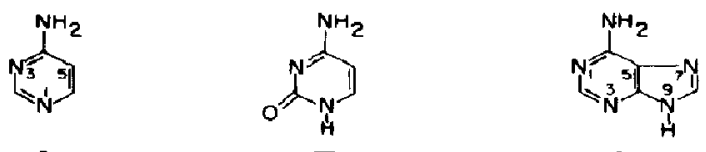

Fig. 1. Formulae for (I) 4-aminopyrimidine, (II) cytosine (4-amino-2-hydroxypyrimidine), and (III) adenine (6-aminopurine). 


\section{EXPERIMENTAL}

\section{Chemicals}

4-Aminopyrimidine was synthesized [15]; its ultraviolet and infrared spectra agreed with the literature data.

Buffer solutions ( $0.5 \mathrm{M}$ ionic strength) were prepared from reagent grade chemicals: (1) $\mathrm{HCl}-\mathrm{KCl}$ ( $\mathrm{pH}$ 0.4-2); (2) McIlvaine ( $\mathrm{pH} 3-8$ ); (3) acetate (pH 4-5). Nitrogen used for deoxygenating was purified and equilibrated by bubbling it successively through acidic V(II) kept over heavily amalgamated zinc, saturated $\mathrm{CaO}$, and distilled water.

\section{Apparatus}

The potentiostat used was a multipurpose instrument, based on solid-state operational amplifiers; its construction, operation, and performance have been described[16]. For phase-selective ac polarography, a Princeton Applied Research Model 122 lock-in amplifier was incorporated. Automatic compensation for series resistance was achieved by positive feedback[17]. Current-voltage and current-time curves were recorded with a Moseley Model $7001 \mathrm{~A}(S) \quad X-Y$ recorder. Rapidly occurring events were recorded with a Tektronix Type 502 oscilloscope and C-12 camera system; the oscilloscope was also utilized as a general purpose monitoring device.

Polarographic and voltammetric measurements were made in a water-jacketed three-compartment cell, kept at 25.0 or $0.5^{\circ} \mathrm{C}$; agar salt bridges were inserted on the counter and reference electrode sides of the medium porosity glass frits separating the compartments. The reference compartment contained a saturated calomel electrode (sce); the counter compartment contained a platinum mesh electrode immersed in saturated $\mathrm{KCl}$ solution. Dme capillaries had drop-times between 6 and $7 \mathrm{~s}$ at potentials of interest and an $m$ value of $1.0 \mathrm{mg} / \mathrm{s}$. A Metrohm E-140 microburet was used to generate the hanging mercury drop electrode ( $h m d e$ ) employed in cyclic voltammetry.

For coulometry, a mercury pool electrode $\left(3 \mathrm{~cm}^{2}\right)$ was used in a water-jacketed cell ( $25 \mathrm{ml}$ capacity), kept at $25^{\circ} \mathrm{C}$ and fitted with a Teflon cap for introduction of sample, salt bridges, and deaeration tubing. Reference and counter electrodes (thermostatted and identical with those used for voltammetry) were connected to the cell via saturated $\mathrm{KCl}$ salt bridges prepared from polyethylene tubes $(2.5 \mathrm{~mm}$ i.d.) fitted at the cell end with $5 \mathrm{~mm}$ lengths of Vycor rod (Corning Code 7930 porous glass).

Ultraviolet spectra were recorded with Cary 14 and Zeiss VSU-2 spectrophotometers; $\mathrm{pH}$ was measured with a Beckman Model G pH meter. Potentials reported are us sce.

\section{Polarographic and voltammetric procedures}

About $10 \mathrm{ml}$ of test solution, prepared by diluting 4AP stock solution with the desired buffer, was added to the cell, purged with $\mathbf{N}_{\mathbf{2}}$ for $15 \mathrm{~min}$, and then examined electrochemically with $\mathbf{N}_{2}$ passing over the solution. The background current, obtained on an identically treated buffer solution, was algebraically subtracted from the observed current.

A natural drop-time was employed for $d c$ polarography; $E_{1 / 2}$ and $i_{d}$ were determined graphically, utilizing the recorder trace. For ac polarography, a controlled $3 \mathrm{~s}$ drop-time and an applied alternating voltage of $50 \mathrm{~Hz}$ and $5 \mathrm{mV}$ peak amplitude $(3.54 \mathrm{mV}$ $r m s$ ) were used; the instantaneous ac current amplitude at the end of the drop-life was recorded.

Cyclic voltammetric data are reported for the first scan except for some indicated situations where subsequent scans were used to follow decomposition processes.

\section{Coulometric procedures}

An aliquot of buffer solution was deoxygenated in the cell for $20 \mathrm{~min} ; \mathrm{Hg}$ was then introduced and the solution electrolyzed at the potential to be employed for electrolysis until the current fell to near zero $(0.01-0.03 \mathrm{~mA})$. The potential was then shifted to $-0.6 \mathrm{~V}$; an aliquot of 4-AP stock solution was added; $\mathrm{N}_{2}$ was vigorously bubbled through the solution until the current dropped to zero (ca. 5 min); electrolysis was begun at the desired potential under a $\mathrm{N}_{2}$ blanket and was stopped when a constant current level (0.1-0.2 $\mathrm{mA}$ ) was reached. Current was recorded as a function of time; coulombs passed during electrolysis were determined by measuring the current-time curve area with a Gelman Model 39231 compensating polar planimeter.

Immediately after each electrolysis, an aliquot of the electrolyzed solution was diluted and examined spectrophotometrically, using an identical concentration of buffer in the reference cell.

\section{Photochemical procedure}

Photochemical irradiation of electrolyzed solutions of 4-AP was made with a RPR lamp ( $3000 \AA$ ) having a photon intensity of $4 \times 10^{17}$ quanta $\mathrm{ml}^{-1} \min ^{-1}$. Solutions were also irradiated at $254 \mathrm{~nm}$ with a Philips TUV $6 \mathrm{~W}$ germicidal lamp, whose radiation was first passed through a $5 \mathrm{~mm}$ layer of $35 \%$ aqueous acetic acid to eliminate traces of radiation below $230 \mathrm{~nm}$. The intensity incident on the $10 \mathrm{~mm}$ pathlength cuvette surface was estimated from the rate of photohydration of a $10^{-4} \mathrm{M}$ aqueous uridine solution in the same cuvette, using the known quant um yield of $2.1 \times 10^{-2}$ for this reaction. When the irradiated solution was to be chromatographed, a ten-fold higher concentration was irradiated in a $1 \mathrm{~mm}$ pathlength cuvette. Ascending chromotography was used with Whatman Nos 1 and 3 papers, and solvent systems of (a) water saturated n-butanol and (b) 2-propanol/concentrated ammonium hydroxide/water $(7: 1: 2)$. Spots were located with a dark ultraviolet lamp and/or by spraying with $1 \mathrm{M}$ alkali and then with $p$-dimethylaminobenzaldehyde.

\section{RESULTS AND DISCUSSION}

Polarographic waves and cyclic voltammetric peaks are designated by Roman numbers with addendum $a$ indicating an anodic faradaic reaction and $c$ indicating a cathodic reaction. 


\section{dc Polarography}

Below pH 2, 4-AP exhibits two cathodic waves, which are of equal height at $\mathrm{pH} 0.4$ (Table 1; Figs 2 and 3). The wave Ic height is constant between $\mathrm{pH} 0.4$ and 3 ; its $I_{d}$ corresponds to a faradaic $n$ of about 3 . The wave IIc height decreases to one-third that of wave I

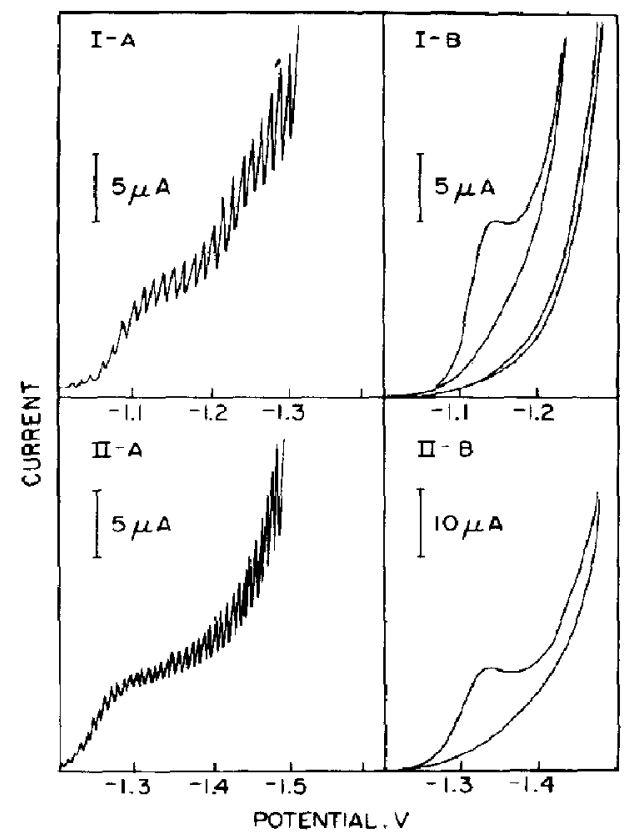

Fig. 2. Dme polarograms (A) and cyclic voltammograms (B) for $0.5 \mathrm{mM}$ 4-aminopyrimidine at pH 0.4 (I) and 3.0 (II). Scan rate on cyclic voltammetry $=0.12 \mathrm{Vs}^{-1}$; background scan is shown in I-B. at pH 1.8 and is zero at pH 3. Above pH 4, wave Ic decreases in a manner characteristic of protonated depolarizers involved in an acid-base equilibrium and is zero at pH 7.5. Wave Ic is diffusion-controlled over the $\mathrm{pH}$ range (current varies linearly with the square root of mercury height $(h)$ and has a temperature coefficient of $1.5-1.7 \% /{ }^{\circ} \mathrm{C}$ ); wave IIc is independent of $h$ at pH 0.4 and slightly linearly dependent at pH 1.8. The $\mathrm{pH}$-dependencies of the half-wave potential $\left(E_{1 / 2}\right)$ are as follows:

Wave Ic : $E_{1 / 2}=-1.070-0.025 \mathrm{pH}(\mathrm{pH} 0.4-2)$

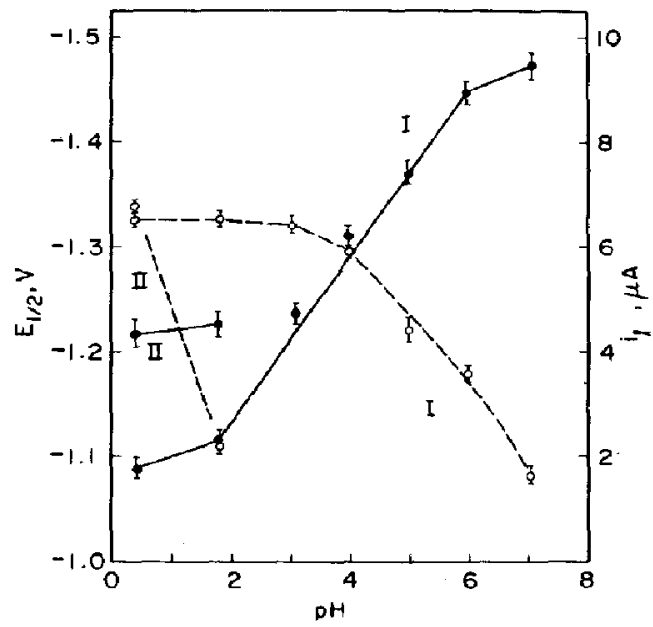

Fig. 3. Variation with $\mathrm{pH}$ of $E_{1 / 2}$ (solid line) and limiting current (maximum $i_{1}$; dashed line) of polarographic waves of 4-aminopyrimidine $(0.5 \mathrm{~m} \mathrm{M})$ in aqueous buffered solution at $25^{\circ} \mathrm{C}$. Successive polarographic waves are indicated by Roman number. Estimated maximum experimental error is indicated, ie $3 \%$ for currents and $20 \mathrm{mV}$ for potentials.

Table 1. dc Polarographic behavior of 4-aminopyrimidine in aqueous media"

\begin{tabular}{llllll}
\hline $\begin{array}{l}\text { Buffer } \\
\text { No. }\end{array}$ & pH & $E_{1 / 2}(\mathrm{~V})$ & $\begin{array}{c}\text { Wave } \\
\text { slopeb(mV) }\end{array}$ & $i_{\mathrm{d}}{ }^{\mathrm{c}}(\mu \mathrm{A})$ & $I_{\mathrm{d}} \mathrm{d}^{\mathrm{d}}$ \\
\hline Wave I & & & & & \\
1 & $0.4^{\circ}$ & -1.080 & 37 & 6.5 & 5.6 \\
1 & 1.8 & -1.115 & 50 & 6.5 & 5.7 \\
2 & 3.1 & -1.235 & 45 & 6.4 & 5.7 \\
3 & 4.0 & -1.310 & 35 & 5.9 & 5.3 \\
3 & 5.0 & -1.370 & 35 & 4.4 & 3.8 \\
2 & 6.0 & -1.445 & 40 & 3.6 & 3.0 \\
2 & 7.1 & -1.470 & 35 & 1.7 & 1.5 \\
Et ${ }_{4} \mathrm{NCl}$ & & -1.43 & & 1.7 & 1.5 \\
Wave $I I$ & & & & & \\
1 & 0.4 & -1.215 & 32 & 6.5 & 5.6 \\
1 & 1.8 & -1.225 & & 2.2 & 1.8 \\
Et $\mathrm{t}_{4} \mathrm{NCl}$ & & -1.70 & & 2.2 & 1.8 \\
\hline
\end{tabular}

- Concentration of 4-aminopyrimidine $=0.5 \mathrm{mM} ; \quad h=65 \mathrm{~cm}$; temperature $=25^{\circ} \mathrm{C}$

b Wave slope $=E_{1 / 4}-E_{3 / 4}$.

c Maximum current.

d $I_{\mathrm{d}}=(6 / 7) i_{\mathrm{d}}(\max ) / \mathrm{Cm}^{2 / 3} t^{1 / 6}$. An approximate value of the faradaic $n$ can be obtained by dividing $l_{d}$ by 2 .

e The ionic strength of $0.4 \mathrm{M} \mathrm{HCl}$ was adjusted to $0.5 \mathrm{M}$ by $\mathrm{KCl}$ addition: the $\mathrm{pH}$ was ca. 0.4 . 


$$
E_{1 / 2}=-0.960-0.080 \mathrm{pH}(\mathrm{pH} \mathrm{2}-7)
$$

Wave IIc: $E_{1 / 2}=-1.207-0.007 \mathrm{pH}(\mathrm{pH} 0.4-2)$

The wave Ic slope somewhat exceeds the ca. $30 \mathrm{mV}$ theoretically expected for a reversible uncomplicated $2 e$ process or for dimerization following a reversible electron transfer [18].

The presence of 4-AP shifts the background discharge positively from about $70 \mathrm{mV}$ in acidic media to $200 \mathrm{mV}$ at PH 7 . This behavior is similar to that of adenine [19].

In $0.1 \mathrm{M} \mathrm{Et}_{4} \mathrm{NCl}$ solution, 4-AP produces two waves of about equal height; $E_{1 / 2}$ and $I_{\mathrm{d}}$ for wave Ic are similar to those in $\mathbf{p H} 7$ buffered solution.

\section{ac Polarography}

In-phase current component peaks I and II (Table 2) correspond to $d c$ polarographic waves Ic and IIc, eg peak II is not seen at pH exceeding 2 . With increasing pH, peak I shifts to more negative potential and decreases in height to vanish above $\mathrm{pH} 7$. The low peak I current, eg $\Delta i_{\mathrm{e}}$ of $1.0 \mu \mathrm{A}$ compared to $15 \mu \mathrm{A}$ calculated for a le diffusion-controlled reversible process, could reflect a slow chemical equilibrium involving the reactant or a rapid equilibrium involving the product of the electron-transfer process. The sharper peaks and larger current magnitudes for peak I indicate that the reoxidation reaction is more prevalent for the first reduction process than for the second (peak II).

A weak depression from background in the quadrature current component (depression I), centered at about $-0.45 \mathrm{~V}$, appears over the $\mathrm{pH}$ range. Weak depression II appears at $\mathrm{pH} 1.8$ following peak II, and increases in magnitude to pH 4 and shifts to more negative potential. At pH 6 and 7, depressions II and III are separated by peak III. It seems probable that the peak I reduction product or its rearrangement product is adsorbed at the solution/electrode interface at $\mathrm{pH}$ exceeding 2 and desorbs at pH exceeding 6 where desorption peak III appears.

\section{Cyclic voltammetry}

The cyclic voltammetric behavior of 4-AP (Table 3; Figure 2) is consistent with its de and ac polarography.
Between pH 0.4 and 2 only peak Ic appears at polarization or scan rate $(v)$ less than $0.2 \mathrm{~V} / \mathrm{s}$, at $v$ exceeding $1 \mathrm{~V} / \mathrm{s}$, peak IIc also appears. Above $\mathrm{pH} 2$, only peak Ic is seen.

The peak Ic current function, $i_{p} / A C v^{1 / 2}(A$, electrode area; $C$, depolarizer concentration) at slow $v(C a$. 37 at pH 4.0) is similar to that for cytosine (34 at pH 4.2), supporting the occurrence of a $3 e$ process. The Ic current functions (Fig. 4) at $\mathrm{pH} 0.4-5$ are relatively constant with increasing $v$ up to $1 \mathrm{~V} / \mathrm{s}$, indicating diffusion control, but then increase with $v$, suggesting the presence of adsorption $[9,20]$; the effect is more evident at pH 5 where the waveheight is decreasing; at pH 6, the function decreases slightly but linearly for $v$ exceeding $\mathrm{ca}$. $0.2 \mathrm{~V} / \mathrm{s}$. The peak IIc current function is constant with increasing $v$ at $\mathrm{pH} 0.4$ but decreases at pH 1.8. The appearance of peak IIc only at $v$ exceeding $1 \mathrm{~V} / \mathrm{s}$ indicates that the species producing it is relatively short-lived.

$E_{\mathrm{p}}$ for peak Ic becomes somewhat more negative with increasing $v$ up to $1 \mathrm{~V} / \mathrm{s}(25 \mathrm{mV}$ at $\mathrm{pH} 0.4$ and 6$)$ but then increases only slightly up to $50 \mathrm{~V} / \mathrm{s}(30 \mathrm{mV}$ at pH 0.4 and 5); the pattern is generally similar to that seen for cytosine[9]. The pH-dependence of $E_{p}$ at the $v$ indicated is as follows:

$$
\text { Peak Ic: } \quad \begin{array}{ll}
E_{p}=-1.10-0.070 \mathrm{pH}(v=0.12 \mathrm{~V} / \mathrm{s})(4) \\
& E_{p}=-1.13-0.070 \mathrm{pH}(v=1 \mathrm{~V} / \mathrm{s})
\end{array}
$$$$
\text { Peak IIc: } \quad E_{p}=-1.365-0.025 \mathrm{pH}(v=20 \mathrm{~V} / \mathrm{s}) .(6)
$$

No anodic peak complementary to peak Ic or IIC appears on the return sweep at $\mathrm{pH} 0.4$ to 5 , even at $v$ $=200 \mathrm{~V} / \mathrm{s}$. However, at pH 6, a very small peak Ia $\left(E_{p}\right.$ $=-1.44 \mathrm{~V}$ ) appears at $v \geqslant 20 \mathrm{~V} / \mathrm{s}$, which seems to be complementary to peak Ic $\left(F_{p}=-1.52 \mathrm{~V}\right)$ and which increases in relative magnitude with increasing $v$; its appearance only at large $v$ indicates the presence of a moderately rapid chemical reaction involving the charge-transfer reaction product[21]; the $80 \mathrm{mV}$ difference in cathodic-anodic peak potentials is somewhat larger than the $60 \mathrm{mV}$ expected for a reversible le redox couple. On the second and subsequent sweeps at $\mathbf{p H ~ 6 , ~ s m a l l ~ c o m p l e m e n t a r y ~ p e a k ~}$ couple IIIc-IIIa appears at $v=50 \mathrm{~V} / \mathrm{s}$, whose height

\begin{tabular}{|c|c|c|c|c|c|c|c|}
\hline \multirow{3}{*}{$\begin{array}{l}\text { Buffer } \\
\text { No. }\end{array}$} & \multirow[b]{3}{*}{$\mathrm{pH}$} & \multicolumn{2}{|c|}{ In-phase component } & \multicolumn{4}{|c|}{ Quadrature component } \\
\hline & & & & Depr & ions ${ }^{b}$ & & \\
\hline & & $E_{\mathrm{s}}(\mathrm{V})$ & $\Delta i_{\mathrm{s}}(\mu \mathrm{A})$ & $E_{\min }(\mathbf{V})$ & $\Delta i_{\min }(\mu \mathrm{A})$ & $E_{\mathrm{q}}(\mathrm{V})$ & $\Delta i_{\mathrm{q}}(\mu \mathbf{A})$ \\
\hline \multirow[t]{2}{*}{1} & 0.4 & I -1.165 & 0.9 & \multicolumn{2}{|c|}{ None } & I -1.19 & 0.30 \\
\hline & & II -1.30 & 0.6 & & & II -1.36 & 0.15 \\
\hline \multirow[t]{2}{*}{1} & 1.8 & $I-1.230$ & 0.85 & II -1.63 & 0.18 & I -1.26 & 0.20 \\
\hline & & II -1.36 & 0.23 & & & II $-\mathbf{1 . 4 1}$ & 0.04 \\
\hline 2 & 3.1 & -1.340 & 0.9 & II -1.71 & 0.45 & I -1.36 & 0.25 \\
\hline 3 & 4.0 & -1.410 & 1.0 & II -1.76 & 0.65 & I -1.44 & 0.22 \\
\hline 3 & 5.0 & -1.445 & 0.7 & II -1.79 & 0.45 & I -1.46 & 0.18 \\
\hline \multirow[t]{2}{*}{2} & 6.0 & -1.500 & 0.4 & II -1.81 & 0.13 & I -1.69 & 0.08 \\
\hline & & & & III -1.94 & 0.28 & III -1.86 & 0.03 \\
\hline \multirow[t]{2}{*}{2} & 7.1 & -1.530 & 0.2 & II -1.83 & 0.10 & I -1.7 & 0.06 \\
\hline & & & & III -1.94 & 0.28 & III -1.88 & 0.05 \\
\hline
\end{tabular}
(as seen on successive sweeps) increases with time

Table 2. ac Polarographic behavior of 4 -aminopyrimidine in aqueous media ${ }^{a}$

ancentration of 4-aminopyrimidine $=0.5 \mathrm{mM}$. Temperature $=25^{\circ} \mathrm{C}$.

b A weak depression from background current, centered at about $-0.45 \mathrm{~V}$, is seen at all $\mathrm{pH}$. 
Table 3. Cyclic voltammetric behavior of 4 -aminopyrimidine in aqueous media"

\begin{tabular}{|c|c|c|c|c|c|c|c|c|c|}
\hline \multirow[b]{2}{*}{ pH } & \multirow{2}{*}{$\begin{array}{c}\text { Scan } \\
\text { Rate }(\mathrm{V} / \mathrm{s})\end{array}$} & & \multicolumn{3}{|c|}{ Peak Ic } & \multicolumn{4}{|c|}{ Peak Ifc ${ }^{\mathbf{b}}$} \\
\hline & & & $E_{\mathrm{p}}(\mathrm{V})$ & $i_{\mathrm{p}}(\mu \mathrm{A})$ & $i_{p} / A C v^{1 / 2}$ & & $E_{p}(\mathbf{V})$ & $i_{p}(\boldsymbol{\mu} \mathbf{A})$ & $i_{\mathrm{p}} / A C v^{1 / 2}$ \\
\hline \multirow[t]{6}{*}{0.4} & 0.014 & & -1.13 & 4.4 & 41 & & & & \\
\hline & 0.12 & & -1.14 & 12.2 & 39 & & & & \\
\hline & 1.0 & & -1.15 & 36 & 40 & & -1.26 & 40 & 44 \\
\hline & 20 & & -1.18 & 180 & 45 & & -1.34 & 190 & 47 \\
\hline & 50 & & -1.18 & 340 & 53 & & -1.37 & 320 & 50 \\
\hline & 100 & & -1.19 & 480 & 53 & & -1.40 & 400 & 44 \\
\hline \multirow[t]{5}{*}{1.8} & 0.014 & & -1.22 & 4.0 & 38 & & & & \\
\hline & $\begin{array}{l}0.12 \\
1.0\end{array}$ & & $\begin{array}{l}-1.23 \\
-1.24\end{array}$ & $\begin{array}{l}12.1 \\
34\end{array}$ & $\begin{array}{l}39 \\
38\end{array}$ & & & & \\
\hline & 20 & & -1.26 & 180 & 45 & & -1.38 & 70 & 17 \\
\hline & 50 & & -1.28 & 320 & 50 & & -1.41 & 150 & 24 \\
\hline & 100 & & -1.28 & 450 & 50 & & -1.42 & 200 & 22 \\
\hline \multirow[t]{5}{*}{3.1} & 0.014 & & -1.30 & 4.0 & 38 & & & & \\
\hline & 0.12 & & -1.32 & 11.5 & 37 & & & & \\
\hline & 1.0 & & -1.33 & 38 & 42 & & & & \\
\hline & 20 & & -1.36 & 175 & 43 & & & & \\
\hline & 50 & & -1.38 & 320 & 50 & & & & \\
\hline \multirow[t]{4}{*}{4.0} & 0.014 & & -1.35 & 4.0 & 38 & & & & \\
\hline & 0.12 & & -1.35 & 11.0 & 35 & & & & \\
\hline & 1.0 & & -1.36 & 36 & 40 & & & & \\
\hline & $\begin{array}{l}20 \\
50\end{array}$ & & -1.40 & 180 & 45 & & & & \\
\hline \multirow[t]{5}{*}{5.0} & 0.014 & & $\begin{array}{l}-1.42 \\
-1.42\end{array}$ & $\begin{array}{l}340 \\
2.9\end{array}$ & $\begin{array}{l}53 \\
27\end{array}$ & & & & \\
\hline & 0.12 & & -1.43 & 8.0 & 26 & & & & \\
\hline & 1.0 & & -1.44 & 25 & 29 & & & & \\
\hline & 20 & & -1.46 & 170 & 42 & & & & \\
\hline & 50 & & -1.46 & 290 & 46 & & & & \\
\hline \multirow[t]{7}{*}{6.0} & 0.014 & & -1.48 & 2.5 & 23 & & & & \\
\hline & 0.12 & & -1.49 & 7.0 & 22 & & & & \\
\hline & 1.0 & & -1.50 & 12 & 13 & & & & \\
\hline & 20 & & -1.52 & 70 & 17 & & & & \\
\hline & & $\mathbf{I a} \mathbf{c}$ & -1.44 & 6 & 1.5 & & & & Peak IIIcd \\
\hline & 50 & & -1.52 & 90 & 14 & & -1.32 & 8.0 & 1 \\
\hline & & $\mathrm{Ia}^{\mathrm{c}}$ & -1.44 & 15 & 2.4 & IIla & -1.26 & 8.0 & 1 \\
\hline \multirow[t]{4}{*}{7.0} & 0.014 & & -1.53 & 1.0 & 9 & & & & \\
\hline & 0.12 & & -1.55 & 1.6 & 5 & & & & \\
\hline & 1.0 & & -1.56 & 2.2 & 2 & & & & Anodic peak \\
\hline & 20 & & & None & & & -1.22 & 5.0 & 1 \\
\hline
\end{tabular}

a Concentration of 4-aminopyrimidine $=0.5 \mathrm{mM}$. Temperature $=25^{\circ} \mathrm{C}$. Area of hmde $=1.8 \mathrm{~mm}^{2}$.

b The current function, $i_{p} / A C v^{1 / 2}$, has been calculated for $A=1.8 \mathrm{~mm}^{2}, C=0.5 \mathrm{mM}$, and $v$ in $V / \mathrm{s}$.

c Anodic peak appears at higher scan rate and results in appearance of the peak IIIc-IIIa couple.

d Peaks IIIc and IIIa increase in magnitude with time ( $f$ text).

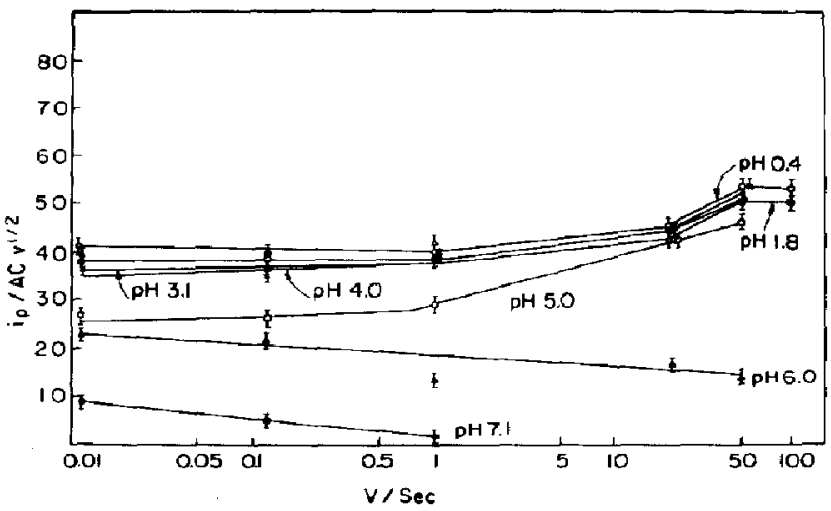

Fig. 4. Variation of current function, $i_{\mathrm{p}} / A C v^{1 / 2}$, with scan rate, $v$, at a hmde for peak Ic of 4-aminopyrimidine at $25^{\circ} \mathrm{C}$. Points are plotted with an indicated error limit of $\pm 3 \%$ of the $i_{p} / A C v^{1 / 2}$ magnitude. pH: open circles, 0.4 ; solid squares, 1.8 ; open triangles, 3.1 ; crosses, 4.0; open squares, 5.0; solid triangles, 6.0; solid circles, 7. 
(30-120 s) while that of peak Ia decreases, suggesting that the species producing peak Ia is transformed by a solution process into the species which produces peak IIIc; the $60 \mathrm{mV}$ difference in the cathodic-anodic peak potentials is characteristic of a $1 e$ reversible redox couple.

At pH 7.0, the height of peak Ic, which diminishes with the concentration of protonated 4-AP, is very small. On the other hand, the rate of transformation of the $3 e$ reduction product of 4-AP into species producing peak pair III--IIIa increases with $\mathrm{pH}$, as can be observed by the enhanced rate of decrease of the absorption peak at $308 \mathrm{~nm}$ at neutral pH. At pH 7.0, only a small peak IIIa is seen at $v$ of $20 \mathrm{~V} / \mathrm{s}$ (whereas peaks Ic-Ia are too small to be measured); this is probably due to the longer lived species responsible for the pink color formed after exposure to air of a 4AP solution reduced at the wave I potential.

\section{Electrolysis at controlled potential}

For three electrolyses at a potential on wave Ic at pH $0.4, n$ (mean and standard deviation) was $2.84 \pm 0.07$ (Table 4); the linear $\log i$ is $t$ plot indicates the reduction to be a relatively clean process. For electrolysis on wave IIc, $n$ could not be estimated exactly due to interference by background discharge; the $n$ of ca. 5 probably corresponds to 3 for wave Ic, 1 for wave IIc and 1 for background electrolysis, or to 3 for Ic and 2 for IIc. At $\mathrm{pH} 4.0, n$ was $2.69 \pm 0.14$ (three electrolyses). At pH 5.0, $n$ was 2.0 ; the $\log i-r$ plot consisted of two linear segments, indicating the presence of a secondary process or processes.

To aid in product identification, $d c$ polarograms were made of the electrolyzed solutions at the $\mathrm{pH}$ of electrolysis and at $\mathrm{pH} 7$; no electroactivity was seen after electrolysis on a wave Ic plateau potential at $\mathrm{pH}$ 0.4. Ultraviolet absorption spectra were also recorded.

Unfortunately, identification of the electrolytic products is complicated by the fact that the reduction products of 4-AP are quite unstable. Thus, on catalytic reduction of 4-AP $[22,23]$, only degradation products of the primary reduction product were isolated or identified, eg $\mathrm{NH}_{4} \mathrm{Cl}$, an acrylamidinium salt and formaldehyde; the cvidence was considered to favor initial formation of the 1,2,5,6-tetrahydro species. In general, catalytic nuclear reductions of pyrimidines give mixtures of products and the tetrahydropyrimidines generally degrade in acidic aqueous medium [24]. Thus, catalytic reduction of pyrimidine in acidic medium leads to the 1,4,5,6-tetrahydro derivative $[23,25,26]$, which rapidly hydrolyzes.

\section{Ultraviolet absorption spectra}

Spectra recorded for the electrolyzed solutions are summarized in Table 5 .

After electrolysis at $\mathrm{pH} 0.4$ at a potential on the wave Ic plateau, the characteristic 4-AP absorption maximum at $246 \mathrm{~nm}$ had been replaced by maxima at 308 and $225 \mathrm{~nm}$; a solution electrolyzed at a wave IIc potential did not exhibit any ultraviolet absorption maximum as would be expected for a $4 e$ reduction of the 4-AP which would leave only one double bond in the ring system.

Electrolysis at $\mathrm{pH} 4.0$ and 5.0 also produced solutions with maxima at 305 and $225 \mathrm{~nm}$.

Although one $\lambda_{\max }$ at both pH 0.4 and $7.0(308 \mathrm{~nm})$ for the 4-AP solution electrolyzed at $\mathrm{pH} 0.4$ differs slightly from that of 305 seen for 4-AP solutions electrolyzed at $\mathrm{pH} 4$ and 5 (Table 5), the difference is unlikely to be significant and it is safe to conclude that the relative constancy of the ratios of the apparent molar absorptivities at the long and short wavelengths, ie 305 or 308 and $225 \mathrm{~nm}$, respectively, at both $\mathrm{pH} 0.4$ (likely to be a protonated species) and 7.0 (likely to be largely a neutral species) of 4-AP solutions electrolyzed at pH 0.4, 4.0 and 5.0 (Table 5) strongly supports the same final products or products being produced on electrolysis with the added implication that the variation in magnitude of the apparent $\varepsilon$ among the reduction products is a measure of the variation in relative amount of one particular final product and/or in the product ratio.

It is helpful to compare the spectral data for 4-AP and its reduction products with the spectral data recorded by Wierzchowski and Shugar[27] for 2,6dimethyl-4-aminopyrimidine and its isomeric rearrangement product, 2-amino-3-cyanopent-2-en-4imine, produced on ultraviolet irradiation (Table 6), eg in respect to $\varepsilon$ ratio and $\lambda_{\max }$.

Table 4. Coulometric estimation of the number of electrons involved in the controlled electrode potential reduction of 4-aminopyrimidine in aqueous media ${ }^{\text {a }}$

\begin{tabular}{|c|c|c|c|c|}
\hline $\mathbf{p H}$ & $\begin{array}{l}\text { Electrolysis } \\
\text { potential (V) }\end{array}$ & $\begin{array}{c}\text { Quantity } \\
\text { of } 4-\mathrm{AP}(\mu \mathrm{mol})\end{array}$ & $\begin{array}{c}\text { Current } \\
\text { passed }(\mathrm{mC})\end{array}$ & $n$ \\
\hline 0.4 & $-1.27^{b}$ & $\begin{array}{l}1.9 \\
1.86 \\
6.0 \\
6.0\end{array}$ & $\begin{array}{r}521 \\
498 \\
1,678 \\
2,975\end{array}$ & $\begin{array}{l}2.84 \\
2.77 \\
2.90 \\
5.14\end{array}$ \\
\hline 4.0 & $\begin{array}{l}-1.40 \\
-1.45\end{array}$ & $\begin{array}{l}6.0 \\
6.0\end{array}$ & $\begin{array}{l}1,628 \\
1,576\end{array}$ & $\begin{array}{l}2.81 \\
2.72\end{array}$ \\
\hline 5.0 & $\begin{array}{l}-1.45 \\
-1.45\end{array}$ & $\begin{array}{l}4.5 \\
6.0\end{array}$ & $\begin{array}{l}1,100 \\
1,163\end{array}$ & $\begin{array}{l}2.53 \\
2.01\end{array}$ \\
\hline
\end{tabular}

n Concentration of 4-aminopyrimidine $=1 \mathrm{mM}$. Temperature

$=25^{\circ} \mathrm{C}$. Background solution was preelectrolyzed.

b This potential is on the weve II limiting current pleateau; in all other cases, the potential was on the wave I plateau.

c Values obtained by subtracting the background current from the total current passed during the electrolysis. 
Table 5. Ultraviolet absorption data for 4-aminopyrimidine and its electrolytic reduction products in aqueous solution

\begin{tabular}{|c|c|c|c|c|}
\hline Solution examined & $\mathbf{p H}^{\mathrm{b}}$ & $\lambda_{\max }(\mathrm{nm})$ & $\varepsilon^{\mathrm{c}}$ & 8 ratiod \\
\hline $\begin{array}{l}\text { 4-Aminopyrimidine } \\
(\mathrm{pK}=5.7)\end{array}$ & $\begin{array}{l}0.4 \\
7.0\end{array}$ & $\begin{array}{l}246 \\
268 \\
233\end{array}$ & $\begin{array}{r}18500 \\
5000 \\
18000\end{array}$ & 0.28 \\
\hline E.P. (wave I; pH 0.4) f & $\begin{array}{l}0.4 \\
7.0\end{array}$ & $\begin{array}{l}308 \\
225 \\
308 \\
225\end{array}$ & $\begin{array}{l}3300 \\
1800 \\
3600 \\
3800\end{array}$ & $\begin{array}{l}1.83 \\
0.95\end{array}$ \\
\hline E.P. (wave I; pH 4.0) ${ }^{f}$ & $\begin{array}{l}0.4 \\
7.0\end{array}$ & $\begin{array}{l}305 \\
225 \\
305 \\
225\end{array}$ & $\begin{array}{l}4500 \\
2000 \\
4600 \\
5200\end{array}$ & $\begin{array}{l}2.25 \\
0.89\end{array}$ \\
\hline E.P. (wave I; pH 5.0) ${ }^{f}$ & $\begin{array}{l}0.4 \\
7.0\end{array}$ & $\begin{array}{l}305 \\
225 \\
305 \\
225\end{array}$ & $\begin{array}{l}6500 \\
2800 \\
4800 \\
5200\end{array}$ & $\begin{array}{l}2.32 \\
0.92\end{array}$ \\
\hline
\end{tabular}

E.P. = product after electrolysis of 4-aminopyrimidine at a potential on the erest of the wave noted at the pH given.

b After electrolysis, the aliquot examined was diluted to the $\mathrm{pH}$ indicated, at which the speetrum was taken.

c In the case of electrolyzed solutions, $\varepsilon$ is based on the original 4AP concentration.

d Where two absorption maxima are reconded, the ratio of $\varepsilon$ at the longer wavelength to $\varepsilon$ at the shorter wavelength is given.

c Literature data for ultraviolet absorption spectrum of 4-aminopyrimidine[33]: at $\mathrm{pH} 0$ (cationic form), $\lambda_{\max }=246 \mathrm{~nm}(\varepsilon=18600)$; at $\mathrm{pH} 13$ (neutral form), $\lambda_{\max }=268 \mathrm{~nm}(\varepsilon=5200)$ and $233 \mathrm{~nm}(\varepsilon=18200)$ ( $\varepsilon$ ratio $=0.29$ ).

f It is helpful to compare the data for the electrolysis products with those reported[27] for 2 amino-3-cyano-pent-2-en-4-imine: Table 6.

Solutions electrolyzed at $\mathbf{p H} 0.4$ turned pink after $2 \mathrm{~h}$ exposure to air; the half-life of the product at room temperature, based on decrease in the $308 \mathrm{~nm}$ peak, is about $70 \mathrm{~h}$. When the $\mathrm{pH}$ of the electrolyzed solution was adjusted to $\mathrm{pH} 3$ or greater, the solution turned pink immediately on exposure to air and the decrease in the $308 \mathrm{~nm}$ peak was much faster, increasing with $\mathrm{pH}$. Solutions electrolyzed at $\mathrm{pH} 0.4$ but stored at $0^{\circ} \mathrm{C}$ under a nitrogen atmosphere were stable over a period of one to two weeks.

Solutions electrolyzed at $\mathrm{pH} 5$ and stored at $0^{\circ} \mathrm{C}$ under a nitrogen atmosphere are stable, showing only a small decrease in absorbance at $305 \mathrm{~nm}$ after two weeks. After $72 \mathrm{~h}$ at room temperature, about $30 \%$ of the product kept at $\mathrm{pH} 0.4$ had decomposed and about $4 \%$ of that kept at $\mathrm{pH} 7$.

\section{Photochemical irradiation of electrolyzed solutions}

Photochemical transformations were attempted in order to see if the 4-AP wave I reduction product

Table 6. U1traviolet absorption data for 2,6-dimethyl-4-aminopyrimidine (I) and 2-amino-3-cyanopent-2-en-4-imine (II)*

\begin{tabular}{|c|c|c|c|}
\hline \multirow[b]{3}{*}{ Compound } & \multicolumn{3}{|c|}{ Absorption maxima $(\mathrm{nm})(\varepsilon)$} \\
\hline & \multirow{2}{*}{$\begin{array}{l}\text { Neutral form } \\
\text { at } \mathrm{pH} 8.15^{c}\end{array}$} & \multicolumn{2}{|c|}{ Protonated form } \\
\hline & & at $\mathbf{p H ~} 5.5^{\mathrm{d}}$ & at $\mathbf{p H} 3^{*}$ \\
\hline $\begin{array}{l}\mathrm{I}^{\mathrm{b}} \\
\left(\mathrm{pK}_{\mathrm{a}}=6.9\right) \\
\varepsilon \text { ratio } \\
\text { II } \\
\left(\mathrm{pK}_{\mathrm{a}}=7.0\right) \\
\varepsilon \text { ratio }\end{array}$ & $\begin{array}{l}265(4700) \\
234(10200) \\
0.46 \\
292(11800) \\
225(13200) \\
0.89\end{array}$ & $\begin{array}{l}301(20500)^{f} \\
225-6\end{array}$ & $\begin{array}{c}302(22000) \\
228(7700) \\
2.86\end{array}$ \\
\hline
\end{tabular}

a Data taken from ref.[27], to whose text and figures citations in the following footnotes refer.

b First protonation site in I is N(3); second protonation site is most likely an amino nitrogen ( $c f$ footnote on page 386). For the doubly protonated form of $\mathrm{I}: \mathrm{pK}_{\mathrm{a}}=-0.14$ (p. 388); $\lambda_{\max }=247 \mathrm{~nm}$ ( $f$ Fig. \$).

c Data estimated from Fig. 4.

- Data estimated from Fig. 3 .

f $\varepsilon$ is based on a quantitative conversion of $68 \%$ of monoprotonated I to monoprotonated II ( $f f$ Fig. 4 of ref.[27]). 
is photochemically oxidized to the parent compound as are the dimeric reduction products of 2hydroxypyrimidine [28] and its derivatives [29, 30], as well to evaluate the photochemical stabjlity of the electrolytic products of 4-AP.

Photochemical exposure in the presence of metallic mercury was examined because the presence of the mercury significantly increased the efficiency of the photochemical transformation. Unfortunately, lack of time prevented exploration of the mechanism of action due to the mercury.

On irradiation $\left(\lambda_{\max }=300 \mathrm{~nm}\right)$ at $\mathrm{pH} 0.4$ of a 4-AP solution previously electrolyzed at $\mathrm{pH} 5.0$, the $305 \mathrm{~nm}$ maximum slowly decreases, shifts to shorter wavelength, and finally disappears (Table 7); if the solution is in contact with mercury, a maximum appears at $235 \mathrm{~nm}$ as the $305 \mathrm{~nm}$ maximum disappears. Exposure at $\mathrm{pH} 0.4$ of an electrolyzed (at $\mathrm{pH}$ 5) 4-AP solution to air in the presence of mercury also results in disappearance of the $305 \mathrm{~nm}$ maximum, and appearance of the $235 \mathrm{~nm}$ maximum $(\varepsilon=20000)$ and of a dc polarographic wave $\left(E_{1 / 2}=-1.13 \mathrm{~V}\right)$, whose height about equals the sum of the two 4-AP waves. Thus, in presence of mercury, ultraviolet irradiation and oxidation by air cause similar transformation of the reduction product(s) of 4-AP. However, it is evident that the photochemical product formed at $\mathrm{pH} 0.4$, while close to 4-AP in several physical properties, is not identical to it, $e g E_{1 / 2}=-1.08 \mathrm{~V}$ and $\lambda_{\max }=246 \mathrm{~nm}$ $(\log \varepsilon=4.27)$ for $4-A P$, but $-1.13 \mathrm{~V}$ and $235 \mathrm{~nm}(4.30)$ for the photochemical product.

Irradiation at pH 0.5 at 254 or $300 \mathrm{~nm}$ in presence of a mercury drop of a 4-AP solution previously electrolyzed at pH 4.0 immediately after electrolysis resulted in decrease of the $308 \mathrm{~nm}$ peak and simultaneous growth of an absorption peak at $245 \mathrm{~nm}$ with all intermediate absorption curves passing through an isosbestic point indicating formation of a single ultraviolet-absorbing photochemical product (Fig. 5). Ultraviolet spectrophotometry and polarography confirmed that the product is 4-AP, as did paper chromat- ography using for comparison an authentic sample of 4-AP ( $R_{f}$ on Whatman No. 1 paper is 0.57 in neutral solvent and 0.76 in alkaline solvent); no other ultraviolet absorbing spots were seen on chromatography but spraying revealed yellow traces presumably due to hydrolytic decomposition.

If the electrolyzed solution is allowed to stand for an hour before irradiation in presence of a mercury drop, the photochemical transformation proceded more slowly and only an absorption maximum at $236 \mathrm{~nm}$ resulted; it is apparent that the final electrolysis

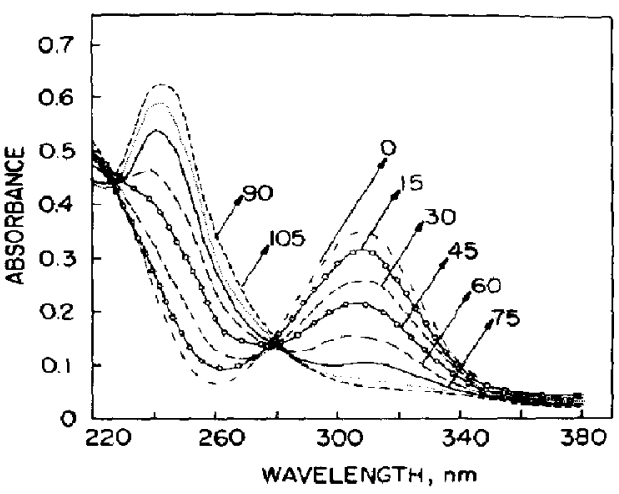

Fig. 5. Photochemical transformation at $\mathrm{pH} 0.4$ on irradiation at $254 \mathrm{~nm}$ of the wave I reduction product of 4 aminopyrimidine in the presence of mercury. Product prepared by complete electrolysis of $2 \mathrm{mM}$ 4-AP at pH 4.0 (0.2 M Britton-Robinson buffer) and subsequent 2.5-fold dilution with $0.4 \mathrm{M} \mathrm{HCl}$. Numbers besides each curve correspond to time of irradiation in minutes. (In comparing Fig. 5 and Table 5 , it should be noted that an acetate buffer and the Cary spectrophotometer were used in obtaining the Table 5 data; the Zeiss instrument, which is much less sensitive than the Cary in the $200-220 \mathrm{~nm}$ region, was used to get the Fig. 5 data.)

Table 7. Transformation of electrolysis product of 4-aminopyrimidinea on ultraviolet irradiation

\begin{tabular}{|c|c|c|c|c|c|c|}
\hline \multirow{3}{*}{$\mathbf{p H}$} & \multirow{3}{*}{$\underset{\text { presence }^{\mathrm{Hg}}}{\mathrm{Hg}}$} & \multirow{3}{*}{$\begin{array}{l}\text { Irradiation" } \\
\text { period } \\
\text { min }\end{array}$} & \multicolumn{4}{|c|}{ Ultraviolet spectra of solutions ${ }^{\star}$} \\
\hline & & & \multicolumn{2}{|c|}{ Before irradiation } & \multicolumn{2}{|c|}{ After irradiation } \\
\hline & & & $\lambda_{\max }$ & $E$ & $\overline{\lambda_{\text {max }}}$ & $\bar{\varepsilon}$ \\
\hline 0.4 & No & 25 & 305 & 6500 & \multicolumn{2}{|c|}{$\mathbf{N A M}^{c}$} \\
\hline 0.4 & Yes & 25 & $\begin{array}{l}305 \\
225\end{array}$ & $\begin{array}{l}6500 \\
2800\end{array}$ & 235 & 20000 \\
\hline 7.0 & No & 25 & $\begin{array}{l}305 \\
225\end{array}$ & $\begin{array}{l}4800 \\
5200\end{array}$ & $\begin{array}{l}300 \\
225\end{array}$ & $\begin{array}{l}3600^{f} \\
4000^{f}\end{array}$ \\
\hline 7.0 & Yes & 15 & $\begin{array}{l}305 \\
225\end{array}$ & $\begin{array}{l}4800 \\
5200\end{array}$ & $\begin{array}{l}300 \\
225\end{array}$ & $\begin{array}{l}3600^{f} \\
4000^{f}\end{array}$ \\
\hline
\end{tabular}

a Solutions were originally electrolyzed at pH 5.0.

b Solutions were irradiated with a RPR 3000 A lamp with a photon intensity of $4 \times 10^{17}$ quanta $/ \mathrm{ml} / \mathrm{min}$.

c $\varepsilon$ values for the reduced solutions were calculated assuming a concentration of the reduction product equal to that of the original 4-aminopyrimidine before electrolysis. Values for dimers should be about twice as great.

d Solution of electrolysis product was irradiated in presence or absence of mercury drop.

- NAM-no absorption maximum observed.

$r$ Ratio of $\varepsilon$ after irradiation to $\varepsilon$ before irradiation equals 0.75 to 0.77 . 
product had undergone a transformation during the hour interval.

Irradiation at pH 7.0 of a 4-AP solution previously electrolyzed at pH 5.0 does not result in photochemical transformation but only in hydrolytic decomposition (Table 7). This behavior would support the view that only the protonated reduction product(s) is photochemically active. On chromatography on Whatman No. 3 paper with neutral solvent, the product absorbing at 225 and $308 \mathrm{~nm}$ gave a spot of $R_{r}=0.26$; with alkaline solvent, only a spot absorbing very faintly at 260 and $320 \mathrm{~nm}$ was found $\left(R_{f}=0.8\right)$, which indicated further decomposition.

Spraying with $p$-dimethylaminobenzaldehyde revealed non-ultraviolet absorbing spots $\left(R_{f}=0.25\right.$ in neutral solvent and 0.79 in alkaline solvent), which became red on exposure to air, as well as traces of yellow decomposition products.

\section{Chemical examination of electrolyzed solutions}

The Nessler test for $\mathrm{NH}_{3}[31]$ was negative for unreduced 4-AP solutions and for 4-AP solutions electrolyzed at pH 0.4 , but was positive for 4-AP solutions electrolyzed at pH 4 and 5 , indicating that deamination of the electrolytic product should be considered as a follow-up reaction at the latter $\mathrm{pH}$. The tetraphenylborate test for $\mathbf{N H}_{3}$, amines, alkaloids and basic nitrogen compounds in general (as well as for potassium] [32] was negative for unreduced 4-AP and for 4-AP electrolyzed at $\mathrm{pH} 0.4 ; 4-\mathrm{AP}$ solutions electrolyzed at pH 4 and 5 gave about twice as much precipitate as would be expected for one amine group, suggesting that, in addition to ammonia produced by deamination ( $c f$. Nessler test), a second amine group may have been generated by ring opening. Such ring opening is known to occur with tetrahydropyrimidines [33] and on adenine reduction [10].

The solution electrolyzed at $\mathrm{pH} 4.0$ gave a negative test for diazotizable amine with Bratton-Marshall reagent [34] and for formaldehyde, which is a possible product of ring cleavage, with chromotropic acid.

Treatment of 4-AP solutions electrolyzed at $\mathrm{pH} 0.5$ and 4 with $p$-dimethylaminobenzaldehyde (with $\mathrm{NaOH}$ ) produced a bright red color, indicating degradation of the pyrimidine ring[35]; 4-AP itself was unaffected. While the $306 \mathrm{~nm}$ peak of a 4-AP solution electrolyzed at pH 4.0 decreased by only $8 \%$ in $30 \mathrm{~min}$, addition of hydroxylamine resulted in its almost total disappearance in $10 \mathrm{~min}$, suggesting that the electrolytic or derived product(s) contains an aldehyde group.

In summary, hydrolysis of reduced 4-AP is more rapid at higher $\mathrm{pH}$. At $\mathrm{pH} 4$, for example, ring opening occurs; ammonia is probably formed, but formaldehyde and a diazotizable amine are not formed (compare to behavior of reduced purine and adenine $[10]$ ).

\section{Isolation of reduction products}

On evaporation under vacuum $(13 \mathrm{mmHg})$ of a $\mathrm{pH}$ 0.4 solution of 4-AP electrolyzed at a wave Ic potential, white crystals precipitated, which, on dissolution in pH
7.0 solution, only absorbed slightly at $235 \mathrm{~nm}$ and which is unstable even at low temperature, eg it turned black on the surface after a few hours of storage in a refrigerator both on exposure to air and under a nitrogen atmosphere. The black residue, obtained on evaporation of the solution remaining after filtering off the whitc erystals, gave on dissolution in pH 7.0 solution absorption maxima at 305 and $225 \mathrm{~nm}$, similar to the 4-AP solutions on completion of electrolysis, including $\varepsilon$ ratio (Table 5); this material is relatively stable in solution, eg about $10 \%$ decrease in absorption after 7 days in a refrigerator.

The presence of two products - one with appreciable absorption at 225 and $305-308 \mathrm{~nm}$ and the other with appreciable absorption only at $235 \mathrm{~nm}$ could account for the variation in the apparent numerical values of the molar absorptivities ( $\varepsilon$ ) (Table 5) for solutions electrolyzed at different times and at different $\mathrm{pH}$ values even though the original solutions were of the same concentration and the $\varepsilon$ ratios for absorption at 308 (or 305 ) and $225 \mathrm{~nm}$ show the same pattern in each instance.

\section{REACTION PATH}

As has been noted, definitive positive identification of the primary electrolytic products of 4-AP with subsequent rigorous formulation of a reaction path, is excluded by the instability of apparently both primary electrolytic products and secondary chemical products, which instability can manifest itself, inter alia, in molecular rearrangement and ring degradation. However, comparison of the electrochemical behavior of 4-AP with those of related compounds, when combined with chemical, spectrophotometric and electrochemical behavior of electrolyzed solutions of 4AP, does allow knowledgeable surmizes to be made concerning the probable primary electrolytic products and their subsequent alteration.

\section{Wave Ic characteristics}

The principal 4-AP wave Ic is seen in aqueous solution between $\mathrm{pH} 0$ and 7 . Comparative $E_{1 / 2}$ and faradaic $n$ data for 4-AP and related compounds (Table 8) are informative, $e g$ some support for common mechanistic factors being involved is provided by the $\mathrm{pH}$-dependencies of $0.08 \pm 0.01 \mathrm{~V}$ for $E_{1 / 2}$ for most multielectron waves and for at least some initial $1 e$ wayes. Calculated and experimental $E_{1 / 2}$ values for pyrimidine and 4-AP are summarized in Table 9 and Fig. 6.

Addition of an amino group at $\mathrm{C}(4)$ in pyrimidine [or at the equivalent $C(6)$ site in purine] makes reduction of the initially reduced pyrimidine $3,4 \mathrm{~N}=\mathrm{C}$ bond (or equivalent purine 1,6 $\mathrm{N}=\mathrm{C}$ bond) more difficult by $0.3 \mathrm{~V}$ or more. Consequently, 4-AP wave I occurs at more negative potential then pyrimidine wave III, which involves $2 e$ reduction of the $3,4 \mathrm{~N}=\mathrm{C}$ bond.

The importance of deamination in the configuration $-\mathrm{NH}-\mathrm{CH}\left(\mathrm{NH}_{2}\right)$, at the 3,4 position, in regenerating the reducible $3,4 \mathrm{~N}=\mathrm{C}$ bond, which would be reduced as formed (ece process), can be estimated by considering the relative contribution of deamination in the 
Table 8. Comparative reduction patterns in aqueous media for 4-aminopyrimidine and related compounds ${ }^{\mathrm{a}}$

\begin{tabular}{|c|c|c|c|c|c|}
\hline Compound & $\begin{array}{c}\mathrm{pH} \\
\text { range }\end{array}$ & pH-de & rendence of $E_{1 / 2}{ }^{b}(V)$ & $n$ & $\begin{array}{c}E_{1 / 2} \text { at } \mathrm{pH} \\
4.2(\mathrm{~V})^{c}\end{array}$ \\
\hline \multirow[t]{5}{*}{ Pyrimidine } & $0.5-5$ & I & $-0.576-0.105 \mathrm{pH}$ & 1 & -1.02 \\
\hline & $3-5$ & II & $-1.142-0.011 \mathrm{pH}$ & 1 & -1.19 \\
\hline & $5-8$ & III & $-0.680-0.089 \mathrm{pH}$ & 2 & $(-1.05)$ \\
\hline & $7-8$ & IV & $-1.600-0.005 \mathrm{pH}$ & 2 & \\
\hline & 9-13 & $\mathbf{v}$ & $-0,805-0.079 \mathrm{pH}$ & 4 & \\
\hline \multirow[t]{3}{*}{ 4-Aminopyrimidine } & $0.4-2.0$ & I & $-1.070-0.025 \mathrm{pH}$ & 3 & $(-1.18)$ \\
\hline & $2.0-7.5$ & I & $-0.960-0.080 \mathrm{pH}$ & 3 & -1.30 \\
\hline & $0.4-2.0$ & II & $-1.207-0.007 \mathrm{pH}$ & 1 & $(-1.24)$ \\
\hline \multirow[t]{4}{*}{ 2-Aminopyrimidine } & $2-2$ & & $-0.685-0.049 \mathrm{pH}$ & 1 & \\
\hline & $4-7$ & I & $-0.425-0.121 \mathrm{pH}$ & 1 & -0.93 \\
\hline & $4-7$ & II & $-1.360-0.004 \mathrm{pH}$ & 1 & -1.38 \\
\hline & 79 & III & $-0.680-0.090 \mathrm{pH}$ & 2 & \\
\hline $\begin{array}{l}\text { 4-Amino-2,6-dimethyl- } \\
\text { pyrimidine }\end{array}$ & $2-8$ & & $-1.130-0.073 \mathbf{p H}$ & 3 or 4 & -1.44 \\
\hline $\begin{array}{l}\text { 4-Amino-2,5-dimethyl- } \\
\text { pyrimidine }\end{array}$ & $1-8$ & & $-1.06-0.076 \mathrm{pH}$ & 3 & -1.38 \\
\hline 2-Hydroxypyrimidine & $2-9$ & & $-0.530-0.078 \mathrm{pH}$ & 1 & -0.86 \\
\hline $\begin{array}{l}\text { Cytosine (4-amino-2- } \\
\text { hydroxypyrimidine) }\end{array}$ & $4 \cdot 6$ & & $-1.125-0.073 \mathrm{pH}$ & 3 & -1.44 \\
\hline \multirow[t]{2}{*}{ Purine } & $1-6$ & I & $-0.697-0.083 \mathrm{pH}$ & 2 & -1.05 \\
\hline & $1-6$ & II & $-0.902-0.080 \mathrm{pH}$ & 2 & -1.24 \\
\hline Adenine & $1-6$ & & $-0.975-0.090 \mathrm{pH}$ & 4 & -1.35 \\
\hline
\end{tabular}

a Data for 4-aminopyrimidine are based on Table $I$; sources of the data for the other compounds are taken from tables in ref. 3 .

$b$ Roman numbers refer to the sequence of waves.

c Values in parentheses have been calculated by the adjacent equations even though the wave in question is not scen at pH 4.2.

electrochemical reduction of cytosine and adenine. In reduced adenine, deamination is relatively slow (rate constant is less than $1 \mathrm{~s}^{-1}$ at $\mathrm{pH} 4$ ) [11]; accordingly, the $d m e$ wave shows a faradaic $n$ of 4 , whereas an $n$ of 6 is found on the longer time scale of exhaustive controlled potential electrolysis (cpe). In cytosine, the hydroxyl substituent on $\mathrm{C}(2)$, which is involved in a tautomeric shift (Fig. 1), has a profound effect, $e g$ the initial $1 e \quad 3,4 \mathrm{~N}=\mathrm{C}$ pyrimidine reduction in 2hydroxypyrimidine occurs energetically more easily (Table 8) and dimerization of the free radical produced is greatly accelerated; the 2-hydroxy substitutent may also accelerate deamination in the 3,4 $-\mathrm{NH}-\mathrm{CH}\left(\mathrm{NH}_{2}\right)-$ configuration [8]. Thus, cytosine is more difficult to reduce initially than pyrimidine; at $\mathrm{pH}$ 5, $E_{1 / 2}$ is $-1.49 \mathrm{~V}$ for cytosine and $-1.13 \mathrm{~V}$ for pyrimidine wave III ( $2 e 3,4 \mathrm{~N}=\mathrm{C}$ bond reduction). However, deamination in cytosine, whose $3,4 \mathrm{~N}=\mathrm{C}$ bond has been reduced, is moderately rapid (rate constant is $10 \mathrm{~s}^{-1}$ at $\mathrm{pH}$ 4)[9]; consequently, deamination is sufficiently rapid for $1 e$ reduction of the deamination product (2-hydroxypyrimidine) to contribute significantly to the observed faradaic dme current, eg $I_{\mathrm{d}}$ is equivalent to $n$ between 2 and 3 , and apparently increases with $\mathrm{pH}$ in the $\mathrm{pH}$ range of $4-6$ where the wave is clear $[8,9] ; n$ on cpe approaches 3.

Based on the behavior of adenine and cytosine, deamination of 3,4-dihydro-4-aminopyrimidine-the expected product of an initial $2 e$ reduction of 4-APto produce pyrimidine would likely be less rapid than in reduced cytosine. Since 4-AP is reduced at more negative potential than that required to reduce the

Table 9. Experimental and calculated half-wave potential data for pyrimidine and 4aminopyrimidine

\begin{tabular}{|c|c|c|c|c|c|c|}
\hline \multirow{2}{*}{ Compound } & \multicolumn{6}{|c|}{$E_{1 / 2}(V)$ at $\mathbf{p H}$ indicated } \\
\hline & pH 0.4 & & $\mathrm{pH} 2.0$ & pH 4.2 & pH 5.0 & pH 7.0 \\
\hline Pyrimidine & $\begin{array}{r}\text { I } \\
\text { II } \\
\text { III } \\
\text { IV } \\
\text { V }\end{array}$ & $\begin{array}{c}-0.62 \\
(-1.15)\end{array}$ & $\begin{array}{l}-0.79 \\
(-1.16) \\
(-0.86)\end{array}$ & $\begin{array}{c}-1.02 \\
-1.19 \\
(-1.05)\end{array}$ & $\begin{array}{c}(-1.10) \\
(-1.20) \\
-1.13 \\
(-1.63)\end{array}$ & $\begin{array}{l}(-1.31) \\
(-1.22) \\
-1.30 \\
-1.64 \\
(-1.36)\end{array}$ \\
\hline $\begin{array}{l}\text { 4-Amino- } \\
\text { pyrimidine }\end{array}$ & $\begin{array}{l}\text { I } \\
\text { II }\end{array}$ & $\begin{array}{l}-1.08 \\
-1.22\end{array}$ & $\begin{array}{l}-1.12 \\
-1.23\end{array}$ & -1.30 & -1.37 & -1.47 \\
\hline
\end{tabular}

a Parentheses around a potential indicates that wave does not appear at $\mathrm{pH}$ in question. The enclosed calculated $E_{1 / 2}$ values are derived from the $E_{1 / 2}-\mathrm{pH}$ equations given in Table 8. Roman numbers refer to the wave sequence. 


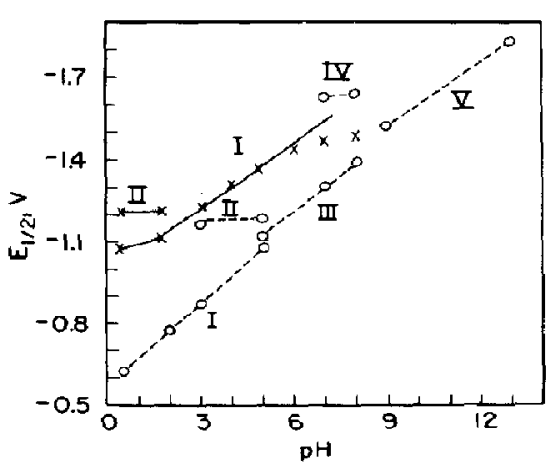

Fig. 6. Variation with $\mathrm{pH}$ of $E_{1 / 2}$ for the polarographic waves of 4-aminopyrimidine ( $0.5 \mathrm{mM}$ ) (solid line and crosses) and pyrimidine (dashed line and circles) in aqueous buffered solutions. Pyrimidine data are taken from ref.[8]. Successive polarographic waves are indicated by Roman numbers.

pyrimidine $3,4 \mathrm{~N}=\mathrm{C}$ bond, the pyrimidine would be reduced as formed, resulting in a second $2 e$ reduction to 3,4-dihydropyrimidine and an eventual $4 e$ reduction of each original 4-AP molecule. However, two pieces of evidence are contrary to this argument. In the range of pH 0.4-4.0, $n$ for the 4-AP reduction, as determined coulometrically, approaches 3 (Table 4) and the dme $I_{\mathrm{d}}$ magnitudes (Table 1) are as expected for $n$ of 3 ; at pH 5 , the coulometric and dme $n$ are 2 . Second, the product of electrolysis at pH 4.0 absorbs at both $\mathrm{pH} 0.4$ and 7.0 at $225 \mathrm{~nm}(\log e=3.30$ and 3.72$)$ and $305 \mathrm{~nm}$ $(\log \epsilon=3.65$ and 3.66) (Table 5) whereas 3,4 dihydropyrimidine at $\mathrm{pH} 3.7$ and 5.8 absorbs at 284 and $285 \mathrm{~nm}(\log \varepsilon=3.04$ and 3.08$)[8]$. The fact that $\lambda_{\max }$ for 4-AP electrolyzed even at $\mathrm{pH} 5$ remains at $305 \mathrm{~nm}$ supports a slow and incomplete deamination; on the other hand, cytosine, electrolyzed at pH 4.5, has the same ultraviolet absorption spectrum as reduced 2 hydroxypyrimidine $[8,36]$.

Alternative approaches for a $3 e$ process must, obviously, provide for deactivation of a free radical, probably by dimerization, and must, in all likelihood, choose between a $2 e$ process (which may involve two almost simultaneous $1 e$ processes), followed by a $1 e$ process or the opposite sequence. The concordance bet ween cpe coulometry and dme polarography at $\mathbf{p H}$ 5 on an $n$ of 2 favors a $2 e$ process followed by a $1 e$ process with the latter not making an appreciable contribution above pH 4, perhaps as a result of a preceding chemical reaction, which produces the reactant for the le process, not occurring sufficiently rapidly at $\mathrm{pH} 5$ even on the cpe time scale. These hypotheses have some support in the slight decrease in coulometric and dme $n$ at $\mathrm{pH} 4$ as compared to lower $\mathrm{pH}$. There is the further consideration that the cpe $\log i$ us $t$ plot is linear at $\mathrm{pH} 0.4$ but consists of two linear segments, indicative of a mother-daughter reaction, at pH 4 and 5 .

The general agreement below $\mathrm{pH} 4$ of the coulometric and dme $n$ values at 3 would indicate that deamination to produce a species reducible at the applied potential either occurs sufficiently rapidly to be essentially complete on the dme time scale or does not occur sufficiently rapidly to contribute to the total current flow on the time scale of cpe. The data support the latter alternative.

The presence of a moderately rapid chemical reaction, coupled to the charge-transfer process, is indicated by the ac polarographic and cyclic voltammetric data, and is evident at pH 6 where a complementary anodic peak is seen at high $v$ on cyclic voltammetry.

The presence of a preprotonation reaction due to only protonated 4-AP being electrochemically reducible in aqueous media, is indicated by the $\mathrm{pH}$ dependence of $E_{1 / 2}$ and, even more, by the decrease in dme faradaic current with increasing $\mathrm{pH}$ in a pattern characteristic of an acid dissociation coupled to a polarographic reduction. The participation of protons in the potential-determining step in reduction of organic substances seems generally to proceed with a preprotonation step; the simultaneous addition of a proton and an electron is scarcely possible for such processes, eg ref.[37]. The protonation rate, if it is rapid enough, does not influence the wave-height, which in this case is controlled by diffusion, but does shift the $E_{1 / 2}[37]$. The $\mathrm{pK}_{\mathrm{a}}$ of 4-AP is 5.7, but it does take up a second proton in strongly acid medium, eg pH 0-2[33].

\section{Kinetics of coupled chemical reactions}

For a diffusion-controlled, reversible electron-transfer process with no associated following chemical reaction (reversible or irreversible), a plot of the cyclic voltammetric current function, $i_{\mathrm{p}} / A C v^{1 / 2}$ vs $v$ is a horizontal straight line. Such a plot for cytosine[9] shows the current function decreasing at high $v$ to a limiting value, which is about $90 \%$ of that calculated for a reversible $2 e$ reduction; from this plot, $k_{\mathrm{f}}$ for the following chemical reaction was estimated to be $10 \mathrm{~s}^{-1}$ and was assigned to deamination of 3,4-dihydro-4amino-2-hydroxypyrimidine.

From the data 4-AP at $\mathrm{pH} 6$ where the plot of $i_{\mathrm{p}} / A C v^{1 / 2}$ vs $v$ is apparently decreasing to a limiting value (Fig. 4), $k_{\mathrm{f}}$ is estimated to be about $2 \mathrm{~s}^{-1}$, indicating a moderately slow chemical reaction, $e g$ the value of $1 \mathrm{~s}^{-1}$ or less estimated for adenine[11].

If the moderately slow follow-up reaction of the previous paragraph is actually due to deamination, it may be possible to estimate a rate constant for an accompanying more rapid follow-up reaction, $e g$ free radical dimerization or carbanion protonation, through the cyclic voltammetric $i_{a} / i_{c}$ ratio. Unfortunately, there are a number of problems in using this ratio for the apparently complementary peak pair seen at pH 6 at large $v$ (Table 3).

At pH 6, the peak Ic current function, $i_{\mathbf{p}} / A C l^{1 / 2}$, has decreased markedly from the presumed $3 e$ level at lower $\mathrm{pH}, e g$ at $v=50 \mathrm{~V} / \mathrm{s}$, it is barely at the level characteristic of a $1 e$ reaction. It is uncertain how much of this decrease can be ascribed to (a) an initial $1 e$ reaction being seen due to a chemical step intervening between it and a subsequent $2 e$ reaction being outrun, (b) the out-running of a chemical step between an intial $2 e$ reaction and a subsequent $1 e$ reaction coupled with incomplete reduction in the initial step, and (c) an overall multielectron process in which only a fraction of the available 4-AP is reduced. The dme $I_{d}$ at pH 6 corresponds to an $n$ of about 1.5 , which is in line with 
the decrease in $I_{\mathrm{d}}$ starting at pH 4 (Table 1; Fig. 3 ).

If $i_{c}$ at $\mathrm{pH} 6$ for $v$ of 20 and $50 \mathrm{~V} / \mathrm{s}$ is assumed to result from $1 e$ reduction to a free radical or radical anion whose oxidation (or that due to a very rapidly produced rearrangement product) is reflected in $i_{\mathrm{a}}$, the rate constant for an intervening dimerization, $k_{2}$, can be approximated from the $i_{\mathrm{a}} / i_{\mathrm{c}}$ ratio for a reversible charge-transfer followed by dimerization[38]. Unfortunately, the latter reference does not include data for peak ratios as low as the 0.086 and 0.167 calculated from the Table 3 data. However, a lower limit for $k_{2}$ can be estimated by using the lowest ratio of 0.436 given in Fig. 4 of ref.[38], which corresponds to $\log \left(k_{2} C_{0}^{*} \tau\right)=1$.00. For a $5 \times 10^{-4} \mathrm{M} 4 \mathrm{AP}$ solution and a switching time $(\tau)$ of less than $6 \mathrm{~ms}, k_{2}$ would exceed $3 \times 10^{6} \mathrm{M}^{-1} \mathrm{~s}^{-1}$. Such a rapid dimerization would be in accord with that of the pyrimidine radical anion in acetonitrile $\left(8 \times 10^{5} \mathrm{M}^{-1} \mathrm{~s}^{-1}\right)$ [39] and the exceedingly rapid dimerizations of pyrimidine and 2 -hydroxypyrimidine free radicals in aqueous media $[8,40]$.

\section{Origin of cyclic voltammetric peaks}

Peaks Ic and IIc originate from the same reduction processes which produce $d m e$ waves Ic and IIc. Peak Ia, which first appears at $\mathrm{pH} 6$, can be ascribed to oxidation of a free radical species produced on $1 e$ or $3 e$ reduction of 4-AP. It is unlikely to be due to oxidation of a hydrodimer, which is normally oxidized only at much more positive potentials. The appearance of this anodic process only at $\mathrm{pH} 6$ may be related to the apparent desorption of the wave Ic product at pH 6 (cf. ac polarographic data); lack of adsorption of a hydrodimer might sufficiently slow down the rate of free radical dimerization so that oxidation of a fraction of the radical can be observed.

The $80 \mathrm{mV}$ difference in peak potentials Ic-Ia would seem to indicate a redox couple; a $60 \mathrm{mV}$ difference is expected for a reversible $1 e$ couple. Formation of a free radical species in peak Ic at $\mathrm{pH} 6\left(E_{\mathrm{p}}=-1.44 \mathrm{~V}\right)$ is supported by the obscrvation of $E_{\mathrm{p}}=-1.38 \mathrm{~V}$ for the $1 e$ reduction of 4-AP in DMSO at a $1: 1$ ratio of 4AP: $\mathrm{HClO}_{4}[41,42]$. Peak IIIc at $-1.32 \mathrm{~V}$ appears only after the emergence of peak la and, accordingly, must be assigned to reduction of a species which is formed as a result of chemical transformation of the peak Ia product.

If deamination is assumed to occur, the free radical formed at $\mathrm{pH} 6$ by $1 e$ or $3 e$ reduction of 4-A P (peak Ic) would probably be oxidized (peak Ia) in near neutral solution to form a dihydropyrimidine, which, after deamination, is converted to pyrimidine. The peak couple IIIc-IIIa at -1.32 and $-1.26 \mathrm{~V}$ could then be due to 1 e reduction of pyrimidine and oxidation of the resulting free radical. The peak IIIc potential is reasonably close to the $-1.27 \mathrm{~V}$ observed for pyrimidine peak IIIc at $\mathrm{pH}$ 6[19]; however, a corresponding anodic peak has never been observed for pyrimidine at pH 6 even at high sean rate $[19,39,40]$. Furthermore, the deamination rate is rather slow at $\mathrm{pH}$ 6. Consequently, it is necessary to conclude that peak couple IIIc-IIIa is due to a species formed by rearrangement which likely involves ring fission. In this connection, it was considered that a chemical reaction other than dimerization might be involved in the disappearance of the pyrimidine radical anion formed on le reduction in acetonitrile[39].

\section{Wave IIc characteristics}

It is difficult to describe the innate characteristics of the electrolytic process or processes involved in the production of wave IIc. Its occurrence only in rather acidic solution $(\mathrm{pH}<2)$ and its decrease in magnitude with increasing pH support involvement of a protonated species, but the relatively slight variation in $E_{1 / 2}$ with $\mathrm{pH}$ [equation (3)] indicates that any protonation-deprotonation reaction is insufficiently coupled to the electron-transfer reaction to affect the latter's energetics; this may be due to saturation protonation of the reacting species since, even at $\mathrm{pH} 2$, the proton activity is over an order or magnitude greater than that of 4-AP or derived species. Cyclic voltammetry indicates that IIc is due to a short-lived species, eg a free radical which dimerizes in preference to being reduced.

The apparent $n$ values for IIc, based on $d m e I_{d}$ is $c a$. 3 at pH 0.4 and 1 at pH 1.8 (Table 1) and, based on cpe coulometry, is ca. 2 at pH 0.4 (Table 4); unfortunately, the possible presence of current resulting from catalytic hydrogen ion reduction connected with the wave I reduction product introduces an uncertainty in the $n$ data. The catalytic character of wave IIc is confirmed by its $E_{1 / 2}$ dependence on the ionic strength; on increase of ionic strength from 0.5 to $3.0 \mathrm{M}$ at $\mathrm{pH} 0.4$, wave IIc shifts negatively and is finally screened by background discharge whereas wave Ic is unaltered at both $\mathrm{pH} 0.4$ and 6.0 by ionic strength increase. The negative shift of a wave with increasing depolarizer concentration and increasing ionic strength is usually assuciated with a catalytic hydrogen wave. However, the temperature and $h$ dependencies of wave Ilc indicate predominantly diffusion control. Such behavior is also seen with adenine in aqueous buffered media[10], where catalytic hydrogen discharge is involved.

\section{Nature of the reduction products}

Two products have been isolated from the macroscale electrolysis of 4-AP, one of which does not absorb in the ultraviolet whereas the other absorbs strongly in the 225 and $305-310 \mathrm{~nm}$ regions. The following discussion is concerned only with the latter product, which is essentially the same within the pH range of $0.4-5$ as indicated by the constancy of the spectrum and of the ratio of $\varepsilon_{30.5}$ to $\varepsilon_{225}$ both at $\mathrm{pH} 0.4$, where the protonated form is being observed, and at pH 7, where the neutral form of the product or a derived species is probably present (Table 5). This product is ascribed to hydrodimers formed following le reduction of 4-AP.

At pH 6 and 7 , the product seems to undergo ring fission, probably as a result of rearrangement with hydrolysis and oxidation being other possible factors. This is suggested by several considerations, eg chemical examination of the reduced solution, appearance of an anodic peak on cyclic voltammetry and nonconversion to 4-AP on irradiation.

Deamination of the product does occur at $\mathrm{pH} 4$ and 5 , but not at $\mathrm{pH} 0.4$. However, the failure of solutions 
electrolyzed even at pH 5 to show appreciable absorption at $285 \mathrm{~nm}$, which is characteristic for solutions of reduced pyrimidine[8], indicates that deamination proceeds rather slowly and does not result in products involving appreciable contributions to the faradaic current or to the ultraviolet spectrum. Apparently in solution whose $\mathrm{pH}$ approaches or exceeds $\mathrm{pK}_{\mathrm{a}}$, slow deamination of the electrolysis product occurs as shown by positive Nessler tests. However, since dimerization is far more rapid than deamination, the product initially produced in such solutions is probably similar to that produced in more acidic media.

Formaldehyde and a diazotizable amine, which are possible products of ring fission, are not produced; however, an aldehyde group may be present. The presence of the latter and of two tetraphenylborate reactive nitrogens per original 4-AP molecule are supportive of ring opening by hydrolysis at the 1,2 $\mathrm{N}-\mathrm{C}$ bond. Such ring opening reactions have been frequently encountered with pyrimidines[43] and purines[44]. Ring opening can also occur as a result of ring-chain tautomerization.

An important property of reduction product II is its sensitivity to photodissociation to monomer following irradiation at 254 or $350 \mathrm{~nm}$. This transformation is accompanied by decomposition as indicated by paper chromatography. Comparison of the apparent $\varepsilon$ of $c a$. 9000 for dimeric reduction product II ( $\lambda_{\max }=308 \mathrm{~nm}$ ) after complete irradiation with $\varepsilon$ of 20000 for 4-AP $\left(\lambda_{\max }=296 \mathrm{~nm}\right)$ indicates that less than $50 \%$ of product II has been transformed into monomer.

\section{Dimer structure}

The initial 1e nucleophilic attack on the pyrimidine ring results in reduction of the $3,4 \mathrm{~N}=\mathrm{C}$ bond and formation of the $4,4^{\prime}$ dimer (or, preferably, hydrodimer) by the free radical produced $[3,8]$.

Since reduced pyrimidines are more basic than the unreduced species [45] and since the hydrodimers produced in the present study are generally protonated, protonation may be at least partially responsible for the shift to longer wavelength on ultraviolet absorption (Table 5). A similar shift is seen for the cationic form of $2,2^{\prime}$-bipyridyl[46], ie $\lambda_{\max }$ are 233 and $278 \mathrm{~nm}$ for the neutral form and 242 and 302 for the protonated form; the $\varepsilon$ ratio for the long wavelength form to short wavelength form for the protonated species is 2.18 , similar to the ratio for the reduced 4-AP forms (Table 5).

Molecular models confirm the relatively rigid structure of the 4,4' hydrodimers of 4-AP resulting from steric hindrance by the amino groups. The resulting close to planar configuration of the two rings can influence the ultraviolet spectrum. The $1 e$ reduction product of 4-AP in DMSO also absorbs at $300 \mathrm{~nm}$ [41].

The fact that in neutral medium, where the hydrodimers should be unprotonated, they have the same ultraviolet spectra but are not converted to the parent 4-AP on photometric irradiation, supports a rearrangement of the dimers on loss of protonation.

Reduction of the $1,2 \mathrm{~N}=\mathrm{C}$ bond, following reduction of the $3,4 \mathrm{~N}=\mathrm{C}$ bond, can result in a free radical which forms a $2,2^{\prime}$ dimer.

\section{Mechanistic pattern}

After allowance is made for reduction product alteration and catalytic hydrogen discharge, the reaction scheme outlined in Figures 7 and 8 seems to fit best the available experimental data for the elec-

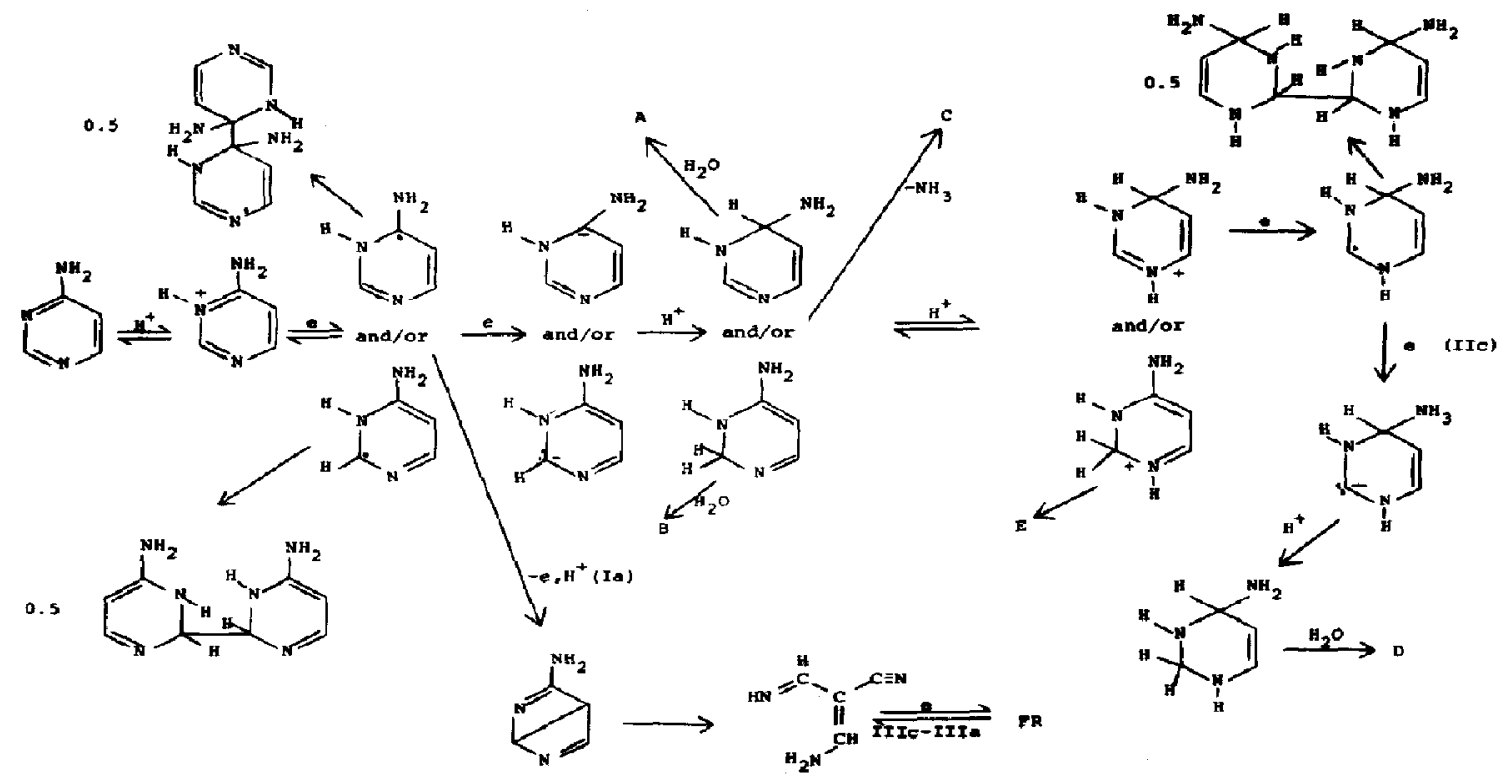

Fig. 7. Proposed reaction pathway for the electrochemical reduction of 4-aminopyrimidine in aqueous media. Some of the species shown can exist in resonant, tautomeric and/or isomeric forms, as well as in protonated and deprotonated states. Upper case letters $A$ through $E$ refer to the reaction path continuations in Fig. 8. FR indicates a free radical. 


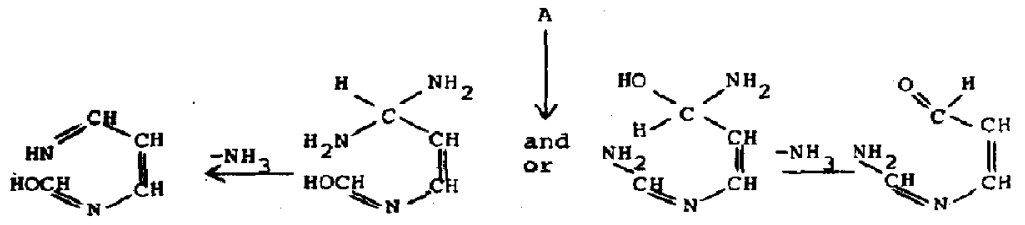

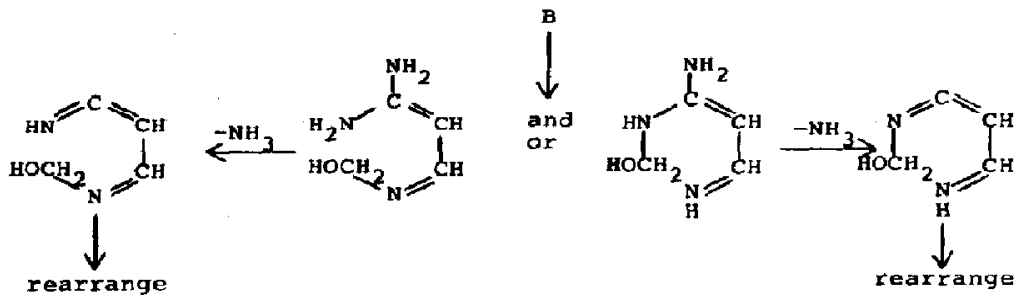

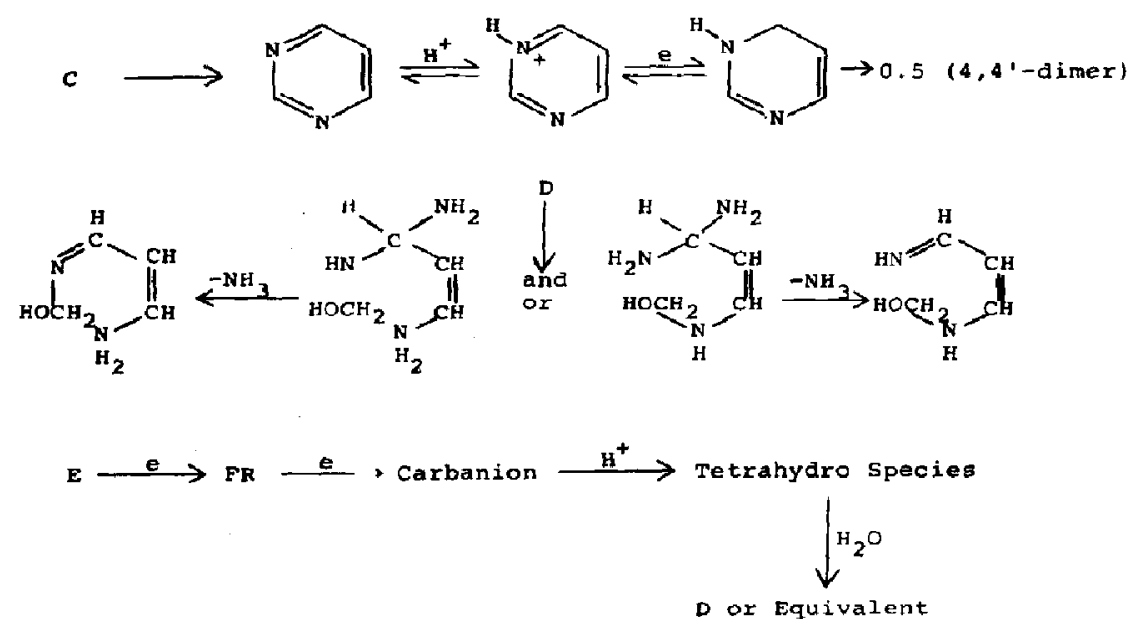

Fig. 8. Proposed reaction pathway for the electrochemical reduction of 4 -aminopyrimidine in aqueous media: continuations of path branches in Fig. 7 as indicated by upper case letters $A$ through E.

trochemical reduction of 4-AP as well as previously well-established patterns for the electrochemical reduction of pyrimidines and purines [3-5].

Protonation of 4-AP occurs at N(3)[47]; this has been confirmed by theoretical calculations [48]. However, the most recent nmr studies [49] on 4-AP derivatives have indicated that $94 \%$ of the 6 -methyl derivative is protonated at $\mathbf{N}(1)$. Consequently, the presence among the reduction and decomposition products of 4-AP of a compound similar to the 2,6dimethyl-4-aminopyrimidine photochemical transformation product, may indicate that, under the conditions used in the present study, a small fraction of the 4-AP is protonated at $N(1)$

The 4-AP itself is reducible only in the protonated state; consequently, the initial potential-controlling le reduction (peak Ic) is preceded by a reversible protonation. The free radical produced can (a) dimerize (probably largely to the $4,4^{\prime}$ species), (b) be reduced by a second electron addition to the $3,4 \mathrm{~N}=\mathrm{C}$. bond to the carbanion since the potential necessary for the first electron transfer is sufficiently negative to cause fur- ther electron transfer and/or (c), above $\mathrm{pH}$ 6, be oxidized (peak Ia).

If the proton activity is sufficiently large, $e g \mathrm{pH} \leqslant 3$, the carbanion path is favored since the carbanion is rapidly protonated to the dihydropyrimidine, which is, in turn, equally rapidly protonated with the resulting positive species being reduced, as formed, to a free radical which rapidly dimerizes, probably predominantly to the $2,2^{\prime}$ species, since the third electron would effectively reduce the $1,2 \mathrm{~N}=\mathrm{C}$ bond.

At very high proton activity, eg $\mathrm{pH} \leqslant 2$, the free radical resulting from the overall $3 e$ addition can, prior to dimerization, be reduced at more negative potential (wave IIc) to a carbanion which is rapidly protonated to form the tetrahydropyrimidine $(1,2,3,4$ species?). The latter species hydrolyzes, opening the ring, probably at the 1,2 position. The reduction involving the fourth electron addition is accompanied by catalytic hydrogen discharge.

At $\mathrm{pH} 4$ and above, the dihydro compound resulting from $2 e$ reduction can deaminate at least to some extent to regenerate the most readily reduced pyri- 
midine $3,4 \mathrm{~N}=\mathrm{C}$ bond with the resulting species, after protonation, being reduced (1e process) to a free radical which dimerizes, probably to the $4,4^{\prime}$ species. At the same time, the dihydropyrimidine can hydrolyze with consequent ring opening; a variety of products are possible with, for example, an aldehyde being formed due to deamination. The relatively slowness of deamination of the dihydroaminopyrimidine as compared to its hydrolysis is indicated by lack of appreciable absorption at $285 \mathrm{~nm}$ as would arise from the presence of dihydropyrimidine or the corresponding hydrodimer[8].

Oxidation at pH $S$ and above of the free radical produced on the initial le reaction does not seem to regenerate 4-AP per se but an isomeric transitory species which undergoes ring opening to species which can form a reversible redox couple (peak IIIc-IIIa).

At least some of the various reduction products can undergo hydrolytic, rearrangement and/or oxidation reactions at differing rates, eg photolytic irradiation regenerates 4-AP only on freshly electrolyzed solutions.

Acknowledgments-The authors thank the National Science Foundation, which helped support the work described, and Dr Tamotsu Wasa, who synthesized the 4-aminopyrimidine and made the preliminary experiments on that compound. Supplementary studies were supported by the Polish Ministry of Science, Technology and Higher Education, in connection with which B.C. thanks Mr Powel Przybora for technical assistance.

\section{REFERENCES}

1. E. Palecek, in Progress in Nucleic Acid Research and Molecular Biology, Vol. IX, pp. 31-73, J. N. Davidson and W. E. Cohn, Eds.). Academic Press, New York (1969).

2. A. L. Underwood and R. N. Burnett, in Electroanalytical Chemistry, Vol. 6, pp. 1-85, (A. J. Bard, Ed.). Marcel Dekker, New York (1972).

3. P. J. Elving, J. E. O'Reilly and C. O. Schmakel, in Methods of Biochemical Analysis, Vol. 21, pp. 287-465, (D. Glick, Ed.). Interscience, New York (1973).

4. P. J. Elving, in Topics in Bioelectrochemistry and Bioenergetics, Vol. I, pp. 180-286, (G. Milazzo, Ed.). John Wiley, London (1976).

5. G. Dryhurst, Electrochemistry of Biological Molecules. Academic Press, New York (1977).

6. T. E. Cummings and P. J. Elving, J.electroanal. Chem. 94 , 123 (1978).

7. T. E. Cummings and P. J. Elving, J. electroanal. Chem. 102, 237 (1979).

8. D. L. Smith and P. J. Elving, J. Am. Chem. Soc. 84, 2741 (1962).

9. J. W. Webb, B. Janik and P. J. Elving, J. Am. Chem. Soc. 95, 991 (1973).

10. D. L. Smith and P. J. Elving, J. Am. Chem. Soc. 84, 1412 (1962).

11. J. W. Webb, B. Janek and P. J. Elving, J. Am. Chem. Soc. 95, 8495 (1973).

12. K. S. V. Santhanam and P. J. Elving, J. Am. Chem. Soc. 96, 1653 (1974).
13. L. F. Cavalieri and B. A. Lowy, Arch. Biochem. Biophys. 35, 83 (1952).

14. Y. Asahi, Yakugaku Zasshi 80, 1222 (1960).

15. D. G. Brown, J. Soc. Chem. Ind. 69, 353 (1950).

16. C. O. Schmakel, Ph.D. Thesis, University of Michigan (1971).

17. P. Delahay and I. Trachtenberg, J. Am. Chem. Soc. 80 , 2094 (1958); R. de Levie and A. A. Husovsky, J. electroanal. Chem. 20, 181 (1969).

18. R. Bonnaterre and G. Cauquis, J. electroanal. Chem. 32, 199 (1971).

19. G. Dryhurst and P. J. Elving, Talanta 16, 855 (1969).

20. R. H. Wopschall and I. Shain, Anal. Chem. 39, 1514 (1967).

21. R. S. Nicholson and I. Shain, Anal. Chem. 36, 706 (1964).

22. R. F. Evans, J. Chem. Soc. 2450 (1964).

23. J. Aft and B. E. Christiansen, J. Org. Chem. 27, 2170 (1962).

24. V. A. Smith and B. E. Christiansen, J. Org. Chem. 20, 825 (1955).

25. D. J. Brown and R. F. Evans, J. Chem. Soc. 4039 (1962).

26. D. J. Brown and R. F. Evans, J. Chem. Soc. 527 (1962).

27. K. L. Wierzchowski and D. Shugar, Photochem. Photobiol, 2, 377 (1963).

28. B. Czochralska and D. Shugar, Biochim. Biophys. Acta 281, 1 (1972).

29. B. Czochralska, M. Wrona and D. Shugar, Bioelectrochem. Bioenerg. 1, 40 (1974).

30. B. Czochralska, D. Shugar, S. K. Arora, R. B. Bates and R. S. Cutler, J. Am. Chem. Soc. 99, 2583 (1977).

31. M. J. Taras, in Colorimetric Determination of Nonmetals, pp. 75-160, (D. F. Boltz, Ed.). Interscience, New York (1958).

32. H. Flaschka and A. J. Bernard, in Advances in Analytical Chemistry and Instrumentation, Vol. 1, pp. 1-117, (C. N. Reilly, Ed.). Interscience, New York (1960).

33. D. J. Brown, The Pyrimidines, John Wiley, New York (1962).

34. A. C. Brattan and E. K. Marshall, J. Biol. Chem. 128, 537 (1939).

35. R. M. Fink, R. E. Cline, C. McGaugey and K. Fink, Anal. Chem. 28, 4 (1956).

36. B. Czochralska and D. Shugar, Experientia Suppl. 18, 251 (1971).

37. S. G. Mairanovski, Catalytic and Kinetic Waves in Polarography. Plenum Press, New York (1968).

38. M. L. Olmstead, R. G. Hamilton and R. S. Nicholson, Anal. Chem. 41, 260 (1969).

39. J. E. O'Reilly and P. J. Elving, J. Am. Chem. Soc, 93, 1871 (1971).

40. P. J. Elving, S. P. Pace and J. E. O'Reilly, J. Am. Chem. Soc. 95, 647 (1973).

41. B. Czochralska and $P$. J. Elving, unpublished results.

42. T. Wasa and P. J. Elving, unpublished results.

43. R. H. Burton and N. O. Kaplan, Arch. Biochem. Biophys. 101, 150 (1963).

44. J. K. Kotchetkova and E. J. Budovsky, Organiczeskaia Chimia Nukleinouyh Kislot. Chimia, Moscow (1970).

45. D. J. Brown, The Pyrimidines: Supplement I, pp. 355-6 and 370, John Wiley, New York (1970).

46. DMS UV Atlas of Organic Compounds, Vol. III. Butterworth and Verlag Chemie, London and Weinheim (1967).

47. M. P. V. Buarland and J. F. W. MuOmie, I. Chem. Soc. 3716 (1952).

48. J. S. Kwiatkowski, Acta Phys. Polonica 30, 963 (1966).

49. J. Riand, M. Th. Chenon and N. Lumbroso-Bader, J. Am. Chem. Soc. 99, 6838 (1977). 